\title{
Lingüística general de Ferdinand de Saussure. El primer curso. Introducción ${ }^{1}$.
}

\section{General linguistics of Ferdinand de Saussure. The First Course. Introduction.}

\author{
Claudia Mejía Quijano \\ Universidad de Antioquia, Colombia \\ lucia.mejia@udea.edu.co
}

\section{Introducción}

A pesar de que durante su vida nunca llegó a publicar lo que originó su gloria póstuma, Ferdinand de Saussure (1857-1913) es considerado actualmente como el fundador de la lingüística moderna por la teoría que le explicó a los jóvenes que asistieron a sus cursos de lingüística general, dictados en francés en la universidad de Ginebra. Algunos de esos estudiantes transmitieron a su vez lo que habían recibido, de manera tan eficaz que el discurso del profesor todavía se puede escuchar hoy en día, más de un siglo después.

La presente edición es el primer ensayo de prolongar en nuestra lengua la transmisión oral de ese pensamiento lingüístico tan novedoso, ahora como entonces, e incluso tal vez más útil en nuestros días, ya que propone herramientas conceptuales que resuelven problemas comunicativos antes desconocidos e introducidos con la revolución informática, pues por primera vez en la historia de la humanidad, existe una realidad comunicativa desconectada de la realidad presente de los hablantes, quienes pueden encontrarse en dos ámbitos espacio-temporales muy diferentes aunque estén "hablando" entre sí.

De los tres cursos de lingüística general, editamos aquí únicamente el primero, no sólo por empezar por el principio, sino porque este curso posee un valor fundamental - lingüístico, científico y cultural.Sin embargo, esta importancia no ha sido totalmente reconocida. Frente al segundo curso, cuya introducción aborda los fenómenos idiomáticos importantes de manera concisa, clara y decidida; y al tercero, en el que los principios generales se entretejen conformando una teoría coherente, el primer curso poco ha llamado la atención. Es cierto que contiene una excesiva cantidad de ejemplos, todos muy pormenorizados, sobre temas demasiado trillados en la época. Además, en este curso no se explica ningún principio general con precisión $\mathrm{y}$, como si fuera poco, sólo se tratan explícitamente los fenómenos de la historia de la lengua, lo que en lingüística ha sido perfectamente menospreciado a partir de mediados del siglo xx.

Sin embargo, después de haber analizado minuciosamente los tres cursos, me atrevo a afirmar que este curso es tan interesante, sino más, que los otros dos: es el más útil para entender el método saussureano y es el más completo de los tres, si se tiene en cuenta que es el único que aborda todos los temas sin excepción, aunque desde luego, a su manera.

¿Por qué entonces se habría subvalorado tanto?

Para poder apreciar correctamente este primer curso, hay que entender la originalidad de la generalización que realiza Saussure.

Estelingüista pasóalahistoria comoun pensador que concibió un sistema teórico coherente, pero él no era un teórico del lenguaje: jamás

1 Esta introducción es un avance del libro de Ferdinand de Saussure, Louis Caille y Albert Riedlinger intitulado Lingüística general. El Primer Curso, que contiene manuscritos inéditos, editados y traducidos por Claudia Mejía Quijano en colaboración con Alexander Pérez Zapata y Daniel Jaramillo Giraldo. Este libro es producto del año sabático otorgado al autor principal por la Universidad de Antioquia (UdeA; calle 70 № 52-21, MedellínColombia). 
escribió ni publicó nada diferente a estudios particulares, completamente concretos sobre temas específicos de lenguas determinadas. Si bien tenía un método didáctico eficaz para hacer comprender el organismo gramatical de las lenguas que enseñaba, jamás se pronunció sobre la manera adecuada de enseñar lenguas. Aunque escribía como pocos han logrado hacerlo, jamás explicó cómo se aprende a escribir bien. A pesar de que traducía admirablemente, nunca describió su manera de transferir un texto de una lengua a otra. Saussure sólo hacía, no le interesaba explicar cómo se debe hacer, salvo cuando se trataba de enseñarle lo que él hacía a sus estudiantes, quienes apreciaban mucho lo que recibían.

Este admirado profesor también era un incansable investigador que se interesaba en todos los campos del lenguaje, tratando de resolver dudas particulares: $i$ en indoeuropeo fue primero la $e$ o la $a$ ? ¿Qué valor tiene el caso del genitivo absoluto en sánscrito? ¿De dónde proviene la palabra wilwan en gótico? ¿Por qué la entonación del lituano remite a un fenómeno evolutivo en indoeuropeo? ¿Por qué las vocales breves del griego antiguo se distribuyen de esa manera en las palabras? ¿Qué letra es la que se puede leer en la primera línea de una inscripción frigia? ¿De dónde viene el encanto de los versos saturninos de la tumba de los Escipiones romanos? ¿Por qué en inglés se dice ai lo que se escribe $i$ como en la palabra mind? Son estos detalles prácticos sobre las lenguas que él conocía, y que él mismo se planteaba incluso en su vida cotidiana, por ejemplo, en sus viajes a Inglaterra o sus vacaciones en Roma, los que constituyeron su campo de acción intelectual durante toda la vida.

En ese sentido, Saussure no era un filósofo ni un lógico, sus principios generales no son elevadas especulaciones, tampoco son desarrollos de observaciones razonables. En cambio, fue un lingüista respetado por las publicaciones en las que presentó soluciones para determinados problemas de las lenguas antiguas. Ahora bien, esta actividad era común en los lingüistas contemporáneos suyos; lo que lo caracterizó especialmente y que le dio renombre en la época, fue que Saussure siempre trató de resolver esos problemas de manera absolutamente científica, poniendo cada vez a prueba sus hipótesis para tratar de confirmarlas, es decir, experimentando con un método riguroso ${ }^{2}$.

Sólo fue cuando le pidieron que diera un curso de lingüística general, y por el interés que sus estudiantes manifestaron en el tema, que Saussure emprendió la tarea de tratar de expresar lo que él había hecho toda la vida, explicándolo con una concepción general del lenguaje. Él mismo señaló a un estudiante de su segundo curso de lingüística general, con bien marcada ironía, que no se consideraba idóneo para dar un curso diferente a los de lingüística histórica, como lo explica Albert Riedlinger, citado por Robert Godel:

«MonsieurdeSaussure [...]craintmanifestement de s'engager; il s'empresse d'ajouter avec un sourire: «Je ne me désigne pas du tout pour faire une linguistique statique», et à mes propositions il ne répond qu'en revenant sans cesse sur la difficulté de l'entreprise». (Godel, 1957a, p. 30)

El Señor de Saussure [...] visiblemente teme comprometerse; y enseguida añade con una sonrisa: "No soy el más indicado para estudiar una lingüística estática" y sólo responde a mis propuestas repitiendo sin cesar que la empresa es muy difícil.

Para entender la sonrisa que acompaña esta frase negativa, hay que tener en cuenta que, en la época, los lingüistas oponían lo generalabstracto a lo particular-concreto. La gramática general (= "lingüística estática" en ese momento) se oponía a la gramática comparada (histórica); y como Saussure no había escrito nada "general», sólo era considerado como el gran maestro de la gramática histórica.

2 El mundo lingüístico sólo empezó a considerarlo un gran pensador desde 1927, cuando J. Kurylowicz encontró la prueba de una hipótesis que Saussure había propuesto en 1878 y que había tratado de corroborar toda su vida - la de un fonema del indoeuropeo cuya existencia se comprobó en una lengua antigua, descubierta después de su muerte y descifrada en 1917 por Bedřich Hrozný (Redard, 1978). 
Tal vez por esto, la profusión de los hechos particulares que Saussure explica en el primer curso pudo haber hecho creer que este curso no era interesante desde un punto de vista general.

Ahora bien, esta oposición lleva a entender la generalización como mera especulación filosófica, como abstracción lógica y razonada, ambas desligadas de los hechos concretos. Muy otra es la concepción saussureana, como lo plantea el mismo profesor desde 1891 y lo volverá a repetir en los tres cursos de lingüística general:

c'est le détail ultime des phénomènes qui est aussi leur raison ultime, et [...] ainsi l'extrême spécialisation peut seule servir effi- cacement l'extrême généralisation. (Saussure,1974, p. 4)

el detalle final de los fenómenos también es su razón final, y [...] por esto para una generalización extrema sólo una extrema especialización puede ser útil y eficaz.

Para Saussure, aunque lo abstracto se distinga de lo concreto, la generalización sólo surge del estudio de los hechos particulares $\mathrm{y}$, por consiguiente, el estudio exhaustivo de las particularidades de las lenguas es el primer paso para generalizar sobre el lenguaje humano.

El primer curso es primordial porque en él encontramos, precisamente, una profusión de casos, que ilustran muy bien lo que se afirma, pero sin que hayan sido inventados; al contrario, habían sido constatados y profundamente estudiados con anterioridad por Saussure mismo. Estos casos reales no se presentan aislados en el curso: cual si fueran los músculos que sostienen un esqueleto, los hechos particulares protegen, envolviéndolo, el método que Saussure utiliza para extraer, de la maraña de ideas de la lingüística de su época, los principios generales. Ese "corpus metodológico" es el tesoro del primer curso: principios generales concretizados en hechos particulares.

El valor del pensamiento general saussureano reside pues en que este lingüista no crea una mera teoría, él concibe ante todo un método. La lingüística general de Saussure no es una suma de ideas verdaderas o falsas, como las doxas saussureana y antisaussureana lo proclamaron a lolargo del sigloveinte; lo queSaussure construyó es un conjunto de principios metodológicos ordenados, que sirven para observar y entender cualquier fenómeno particular del lenguaje.

El alcance general de ese método sobrepasa la lingüística: en sus explicaciones del primer curso el profesor ginebrino plasmó un método eficaz, pero también un método reproducible con el que se pueden abordar los fenómenos comparables a las lenguas humanas; o sea, un método científico para las disciplinas que, como la lingüística, estudian los productos mentales de los seres humanos, disciplinas que Saussure agrupó teóricamente en lo que él llamó la Semiología.

En este primer curso, Saussure explica el hecho particular y extrae el principio general delante de sus estudiantes, en el acto mismo de la exposición. En los otros dos cursos, la exposición toma otras formas: en el segundo curso, las nociones generales se presentan en la introducción y se encuentran separadas de los hechos particulares, desarrollados a lo largo del curso. En el tercer curso, al revés, primero empieza por lo particular y termina con lo general afianzándose la separación entre lo que Saussure llama entonces las lenguas (lo particular) y la lengua (lo general), aunque el profesor afirma explícitamente que esta separación sólo es un artificio didáctico. El acto de generalizar implica el estudio de lo particular, pero la exposición de los principios generales bien puede separarse de la explicación de lo particular. Esta diferencia es la que observamos entre los tres cursos. Únicamente en el primer curso vemos lo particular y lo general tratados a la par, combinados con tal maestría que los lingüistas interesados en los hechos particulares, si bien entienden la fineza y la originalidad de los análisis para la época (Petit, 2013), no alcanzan a vislumbrar del todo el alcance general de los principios utilizados; y los generalizadores, un tanto perdidos en el hormigueo de hechos particulares, sólo atinan a intuir el germen del principio general, sin alcanzar a divisar las múltiples ramificaciones (Godel 1957a, 1958; Mejía Quijano 1998a). 
Para acceder a la gran riqueza que encierra el primer curso necesitamos entonces entender que lo que en él encontramos no es simple teoría ilustrada con ejemplos concretos, sino el análisis de problemas particulares de la época, cuya solución lleva a descubrir los principios generales encarnados en ciertas lenguas, poco conocidas entonces y actualmente aún más exóticas.

En este curso, Saussure lleva de la mano a sus estudiantes utilizando el método para examinar en cada tema lo que la lingüística de su época concebía como general, explicándoles al mismo tiempo de manera exhaustiva cada parte del método. A cada paso, se diría que Saussure está aludiendo a los principios generales, pareciera como si para explicar el fenómeno él "aplicara" el principio, pero es más bien, o es también, tratando de entender el fenómeno que Saussure encuentra el principio de explicación. Este doble trabajo simultáneo da frutos inesperados: en este primer curso vemos cómo, siguiendo cuidadosamente lo que cada vez afirma con los casos, el profesor va a hacer aflorar, poco a poco, las ideas generales de la masa de ideas confusas vehiculadas en la época. El descubrimiento del acto de hablar es el fruto más visible, principio general que sólo en el tercer curso se va a imponer al lado de la lengua, pero de tal manera que obligaría entonces al profesor a imaginar dos ciencias lingüísticas distintas. (Mejía Quijano, 2012a).

Entender esta doble actividad es difícil para el lector de las notas. En este primer curso, Saussure se encuentra sin cesar en un vaivén entre lo particular y lo general, lo que crea una trampa conceptual pues es muy fácil ver sólo un aspecto: un sinfín de ejemplos eruditos un tanto apabullantes, o una que otra afirmación general suelta que no conduce muy lejos. Sin embargo, si se estudian en detalle los casos analizados y el fenómeno correspondiente, se puede ver cómo todos los principios ya están ahí, sosteniendo el análisis y a su vez mostrando sus ramificaciones, con su carácter general que permite la extrapolación.

Elcapítulo sobrela escritura, por ejemplo, puede ser la base de un estudio científico, urgentemente necesario, sobre los equívocos y malentendidos propiciados por los medios informáticos. El capítulo sobre la etimología popular es ejemplar del análisis de las patologías del lenguaje, tanto las patologías del aprendizaje en los niños como las de las enfermedades degenerativas. La medicina se ahorraría esfuerzos inútiles si los neurólogos que se interesan en el lenguaje tuvieran la curiosidad de estudiar los fenómenos evolutivos de las lenguas; los neurocientíficos entienden mejor el alcance de la plasticidad cerebral si contemplan lo específico del cambio lingüístico (Ansermet y Magistretti, 2004, 2010). El capítulo de los cambios fonéticos es una demostración "de campo" sobre el rigor en las ciencias humanas, que plantea cuán necesario es, para un verdadero estudio científico, el situarse en un punto de vista prospectivo o retrospectivo y la gran diferencia que esto implica en la consideración misma de cualquier fenómeno humano.

Los estudiantes de Saussure sabían que ese profesor no enseñaba un saber simplemente teórico, todos lo mencionan en sus testimonios, como Albert Riedlinger en una carta que le escribe a su maestro en 1911:

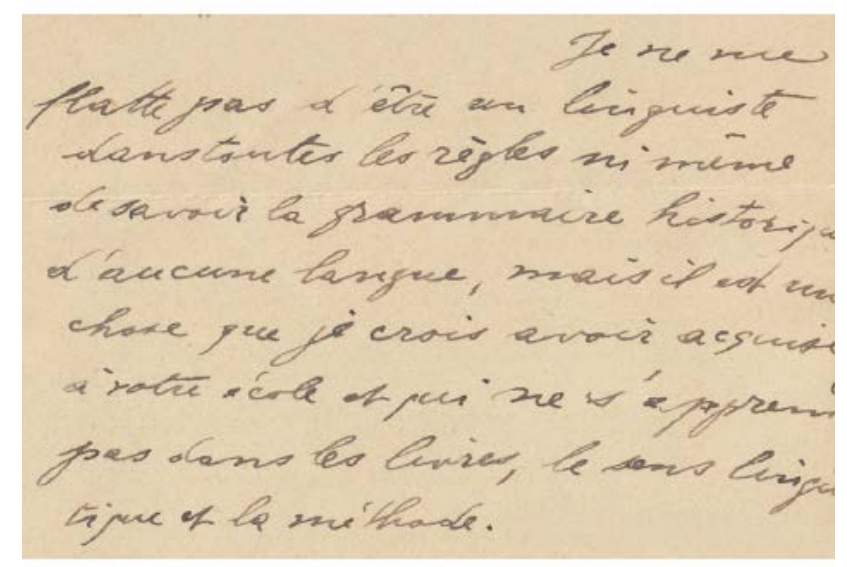

Manuscrito conservado en el Castillo de Vufflens (Mejía, 2015)

No me vanaglorio de ser un lingüista con todas las de la ley, ni siquiera de saber la gramática histórica de ninguna lengua, pero hay algo que creo haber adquirido con su enseñanza y que no se aprende en los libros: el sentido lingüístico y el método.

De la primera a la última frase, el primer curso de lingüística general de Ferdinand de 
Saussure es un modelo metodológico con un alcance inconmensurable, porque el método que entraña es general al fenómeno idiomático y ¿cuál actividad humana no está inmersa en el lenguaje?

\section{Una transmisión oral, por escrito}

Ferdinand de Saussure es ampliamente conocido como el autor de un libro que él no escribió. Fueron dos colegas suyos, Charles Bally y Albert Sechehaye, quienes escribieron una compilación de una parte del contenido de los cursos que Saussure dictara sobre la lingüística general. Esta compilación intitulada Curso de lingüística general (Curso), publicada en francés en 1916 y traducida al español en 1945 por Amado Alonso, se convirtió en el libro más influyente de toda la lingüística del siglo veinte, pues algunas ideas que contenía fueron desarrolladas por importantes lingüistas como Luis Hjelmslev (1928, 1942, 1943), Eric Buyssens (1942, 1943) y Nicolas Trubetzkoy (1939), por no citar sino los primeros lectores, cuyo trabajo formó la base del estructuralismo lingüístico, movimiento que a mediados del siglo se extendió a otras disciplinas humanas como la antropología con Claude Lévi-Strauss (1958), el sicoanálisis con Jacques Lacan (1966) y la literatura con Roland Barthes (1964).

Para el público en general y para la mayoría de los jóvenes lingüistas, el Curso de $1916 \mathrm{y}$, por consiguiente, las teorías que este libro contiene, son ya un hecho pasado y asimilado, que pertenece pues a la historia de la lingüística del siglo veinte y no al debate actual de la disciplina. Esto es indiscutible si nos referimos a las teorías expuestas por Bally y Sechehaye en ese libro, aunque no podemos afirmar lo mismo de lo que el profesor dictó en los cursos de lingüística general, que se transmitió con otro material, diferente y anterior al Curso, a saber los cuadernos de los estudiantes que asistieron a dichos cursos.
Los documentos originales de los estudiantes que registraron el discurso del profesor no están propiamente "escritos", sino que son una combinación singular de expresión oral y permanencia escrita.

Estos documentos exigen una lectura un poco ardua, que conlleva sinembargo resultados fecundos. En esta presentación, trataremos de explicitar los componentes de la peculiar trasmisión oral que nuestra edición semiológica intenta continuar en nuestra lengua, y empezamos examinando las diferencias entre los dos materiales que poseemos actualmente.

\subsection{Los cursos, y el Curso, de lingüística general}

Porsucarácterdecompilación, suscontradicciones y ambigüedades, desde el principio el Curso de Bally y Sechehaye suscitó en el campo lingüístico muchas controversias sobre la interpretación del pensamiento saussureano. Cuando se publicó en 1916, dos excelentes estudiantes de Saussure, Antoine Meillet (1916) y Paul F. Regard (1918), lo criticaron abiertamente pues no reconocieron en ese libro lo que habían recibido de su maestro ${ }^{1}$. Más tarde las controversias continuaron sobre la interpretación precisa de puntos clave del pensamiento saussureano, como la dualidad lengua-habla (Buyssens, 1942; Prieto, 1975, 1982), la distinción diacronía-sincronía (Jakobson, 1931; Wunderli, 1980), lo arbitrario del signo (Coseriu, 1977).

Estos debates empezaron a apaciguarse un poco con el trabajo de Robert Godel (1954, 1957a, 1957b, 1958, 1960a) y de Rudolf Engler (19681974), quienes publicaron las fuentes manuscritas del Curso mostrando que este libro era fiel a la letra de los cuadernos de algunos estudiantes, aunque también mostraron su infidelidad al sentido de lo dictado por el profesor, infidelidad en ambos niveles cuantitativo y cualitativo.

A nivel cuantitativo, señalemos que el Curso no contiene sino aproximadamente el $40 \%$ de

1 Sobre este primer debate que empieza poco después de la muerte de Saussure en febrero de 1913, véase aquí mismo el artículo "Les cours de linguistique générale de Ferdinand de Saussure, un projet de Paul-F. Regard et Antoine Meillet". 
la materia abordada en los cursos, lo que se explica no sólo por el considerable volumen de las fuentes, sino también, y sobre todo, por la estrecha interpretación que Bally y Sechehaye le dieran al pensamiento general de Saussure, que los llevó a excluir de su libro el extenso material sobre los hechos particulares.

El trabajo de Godel y Engler, que se contempló primero como una exégesis del libro de 1916, suscitó desde la década de los sesenta un interés creciente por todo tipo de documentación original sobre la actividad lingüística de Saussure, a saber no sólo los manuscritos autógrafos, sino también los manuscritos de sus últimos alumnos, que contienen precisamente la transmisión oral del legadogeneral deSaussure. Muchos investigadores han ido publicando lenta pero constantemente estos manuscritos: en la actualidad ya conforman una nueva obra póstuma bastante considerable e independiente del Curso por completo. Vale la pena presentar aquí las ediciones más importantes (las referencias precisas se relacionan en la bibliografía al final del libro):

1957 Primeras lecciones del segundo curso de lingüística general. Reconstrucción a partir de varios cuadernos de estudiantes.

1960 Recuerdos sobre su juventud y sus estudios. Manuscrito autógrafo: BPU Ms. fr. 3957-1.

1968-1974 Edición crítica del Curso, incluye transcripciones de extractos casi completos de la mayoría de los cuadernos de los estudiantes de Saussure.

1978 Ensayo de adolescencia sobre las raíces del griego, del latín y del alemán. Manuscrito autógrafo: Harvard Houghton Library. BMs. Fr. 266(2).

1980 Extractos del curso de fonética griega y latina de 1909-1910. Cuadernos de Albert Riedlinger.

1986 Extractos de la investigación sobre las leyendas germánicas. Manuscritos autógrafos, BPU: Ms. fr. 3958-3959.

1987 Transcripción incompleta del tercer curso de lingüística general. Cuadernos de Emile Constantin, BGE: Ms. fr. 3972.

1988 Dieciocho notasetimológicas. Manuscritos autógrafos, Biblioteca del Colegio de Francia. Documentos de Antoine Meillet: MD 1.18.
1990 Notas preparatorias para un curso de morfología indoeuropea dictado en Paris. Manuscrito autógrafo, BPU: Ms. fr. 3970c.

1993a Transcripción incompleta del primer y del tercer curso de lingüística general. Cuadernos de Albert Riedlinger, BGE: Cours universitaires 761-1/3 y de Emile Constantin, BGE: Ms. fr. 3972.

1993b Transcripción incompleta y traducción al inglés del tercer curso de lingüística general. Cuadernos de Emile Constantin, BGE: Ms. fr. 3972.

1995a Notas sobre Fonética. Manuscritos autógrafos, Harvard Houghton Library: BMs. Fr. 266.

1995b Extractos del curso de Gramática comparada del griego y del latín (1907-1908). Cuadernos de Albert Riedlinger, BGE: Cours universitaires 824 .

1996 Transcripción incompleta del primer curso de lingüística general y traducción al inglés. Cuadernos de Albert Riedlinger, BGE: Cours universitaires 761-1/3.

1997a Transcripción incompleta del segundo curso de lingüística general. Cuadernos de Albert Riedlinger, BGE: Cours universitaires 761-4 y de Charles Patois, BGE: Ms. fr. 3971.

1997b Reproducción en facsímile de la nota «alka». Manuscrito autógrafo, BPU: Ms. fr. 3951-9.

2002a Teoría de las sonantes. Manuscrito autógrafo, BPU: Ms. Fr. 3955-1.

2002b Escritos de lingüística general. Transcripción incompleta del manuscrito autógrafo, BGE: Arch. de Saussure 272.

2003a Extractos de las notas sobre la acentuación lituana. Manuscrito autógrafo, BGE: Ms. fr. 3953.

2003b Extractos de las notas sobre las leyendas germánicas. Manuscrito autógrafo, BGE: Ms. fr. 3958 y Ms. fr. 3959.

2006a Transcripción integral del Tercer curso de lingüística general. Cuadernos de Emile Constantin, BGE: Ms. fr. 3972.

2006b Notas preparatorias para el tercer curso de lingüística general. Manuscrito autógrafo, BGE: Ms. fr. 3951-23; Archives de Saussure 372.

2007 Reproducción en imágenes digitales de la «Nota Whitney», Manuscrito autógrafo, BGE: Ms. fr. 3951-10.

2008 Escritos literarios de adolescencia. Manuscrito autógrafo, BGE: Archives de Saussure 369 y 370. 
2009 Traducción del Agamenón de Esquilo. Manuscrito autógrafo, BGE: Archives de Saussure 369, 372, 381, 382-387; Ms. fr. 3953 y 3957.

2011 Ciencia del lenguaje. Transcripción incompleta del manuscrito autógrafo, BGE: Arch. de Saussure 372.

2013a Anagramas homéricos. Manuscrito autógrafo, BGE: Ms. fr. 3963.

2013b Curso de Etimología griega y latina. Cuadernos de Louis Brütsch, BGE: Ms. fr. 3971.

2014 Correspondencia 1866-1913. Manuscritos autógrafos, más de 600 cartas conservadas en bibliotecas y fondos privados.

Estas publicaciones de los manuscritos de Saussure y de sus alumnos, que no representan sino un mínimo porcentaje de lo que se conserva en diversas bibliotecas pero especialmente en la Biblioteca de Ginebra (BGE, anteriormente BPU), ya han propiciado que surjan facetas desconocidas dela teoría, aunque primero permitieron comenzar a entender lo ajena que era la interpretación de los editores del Curso. Aunque Bally y Sechehaye sí conocieron a Saussure de jóvenes, ellos no asistieron a los cursos de lingüística general y como ya tenían una idea clara de lo que ellos consideraban general en el lenguaje, leyendo los cuadernos de los estudiantes, no pudieron entender, lo suficiente como para expresarlas de manera adecuada, la mayoría de las novedades expuestas por Saussure al final de su vida.

Esta diferencia entre lo que se lee en el Curso y lo que se oye en Los cursos sólo se ha ido descubriendo poco a poco, pero ya los especialistas lo aceptan sin debates (Bouquet, 2010; Depecker, 2008, 2009a, 2009b; Godel, 1957a; Fehr, 19972002; Mejía Quijano 1997, 1998a, 1998b, 1999a, 1999b, 2006a, 2006b, 2009a, 2009b, 2012a; Mejía Quijano, Jaramillo Giraldo y Pérez Zapata, 2016; Rousseau, 2006; Petit, 2010a, 2010b; Petit y Mejía Quijano,2009,Sofía, 2013, 2015), y la manera como se estudia a Saussure ha cambiado gradual pero radicalmente: del ícono de los estructuralistas autor monolítico de un manual cuyo contenido reducido a algunas máximas se convirtió para muchos en dogma, Saussure ha pasado a ser un hombre de carne y hueso, enmarcado en su época, y con una teoría que evolucionó a lo largo de su vida, según los descubrimientos que iba realizando en los numerosos campos de su actividad intelectual.

Como las ideas de Saussure se desarrollaron constantemente, sólo desdehace pocose ha podido empezar a apreciarlas de esta manera dinámica, que demuestra la considerable diferencia entre lo expuesto en los cursos y lo que se encuentra en el Curso, libro que, además de reducir la materia dada, trató de reunir en uno solo, los tres cursos dictados por Saussure, borrando así las particularidades históricas de cada uno. Actualmente los tres cursos de lingüística general, dictados sólo año de por medio, se conciben, por el contrario, en un marco evolutivo: aunque se complementan entre sí, cada uno representa una etapa diferente en la construcción de una teoría coheren- te (Depecker, 2008, 2009a, 2009b; Mejía Quijano, 1998a, 2006b, 2009a, 2009b, 2012a).

Este cambio de perspectiva hacia el estudio cronológico de los manuscritos saussureanos todavía se sigue realizando: hasta el momento se ha editado aproximadamente el $70 \%$ de la materia de los cursos aunque sólo los cuadernos de 3 estudiantes, o sea aproximadamente el 30\% de los manuscritos existentes. Sin embargo, el auge de los estudios saussureanos basados en estos manuscritos ya puede apreciarse con la publicación de recientes traducciones de los cursos en otras lenguas diferentes al francés, como en inglés (Saussure, 1993b - traducción de Roy Harris; 1996 y 1997a - traducción de Georges Wolff), y alemán (Fehr, 1997; Kaudé, 2002). Sabemos que se prepara la publicación de traducciones al japonés y al koreano de la edición integral de los cuadernos de Emile Constantin del Tercer curso de lingüística general (2006a). También se han traducido, a más de diez lenguas diferentes, los manuscritos autógrafos de Saussure sobre la Ciencia del lenguaje, que sólo se descubrieron recientemente.

\subsection{Esta edición bilingüe}

Hasta hoy, ningún curso completo de Saussure había sido traducido al español. Ahora bien, el lector no sólo encontrará aquí la primera traducción al español del curso de lingüística general de 1907, sino también la primera edición 
integral en francés de los únicos manuscritos de primera mano que se conservaron, y que seguían todavía inéditos: uno porque apenas se descubrió en el 2010, el otro porque estaba escrito en taquigrafía y sólo unas cuantas páginas habían sido descifradas y publicadas por Rudolf Engler desde 1968.

Esta edición tiene pues el privilegio de llenar dos vacíos en ambas lenguas, gracias a un trabajo de equipo que merece una explicación pormenorizada.

Empecemos señalando que, como se observa a primera vista en el formato editorial que escogimos, aunque editamos dos manuscritos en francés, que señalamos con las iniciales de sus autores: LC para la taquigrafía de Louis Caille y AR para las notas de Albert Riedlinger, no presentamos sino una sola traducción al español.
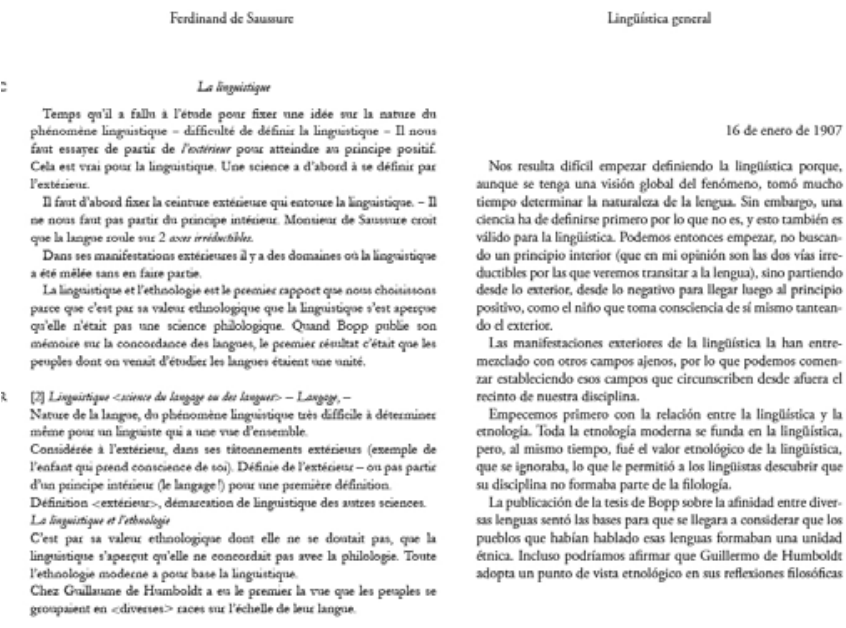

Los manuscritos en francés son notas tomadas durante el curso, o sea que se trata de textos muy singulares: uno contiene frases elípticas, a veces mal escritas o sin terminar, llenas de abreviaciones; el otro, más elaborado, es sin embargo escueto y condensado, y no presenta muchos enlaces sintácticos explícitos. Ambos textos a su manera exigen pues una lectura meticulosa, que se facilita en nuestra edición ya que se encuentran ambos en la misma página, lo que permite compararlos: ellector francohablante puede entonces complementar la información que recibe y deducir en cierta medida el discurso original, ya que se trata de fuentes de primera mano, sin ningún intermediario entre la letra y la expresión oral del profesor.

En este sentido, la edición diagramática de Rudolf Engler de 1968 que contiene cuatro y a veces cinco versiones de la misma lección sigue siendo el mejor instrumento de interpretación que poseemos actualmente para los demás cursos.

Ahora bien, para nuestra edición bilingüe ¿cuál hubiera sido el interés de traducir las versiones de ambos estudiantes? Literales, estas notas son bastante equívocas y cuando se intenta escribir un texto más legible, la interpretación implícita del traductor se inmiscuye en la traducción, quiérase o no. Con las traducciones de las notas no se podría realizar entonces la misma comparación que en francés: una traducción nunca es una fuente de primera mano. En francés, la comparación puede dar una idea del discurso del profesor, en español daría una idea algo borrosa, pues inevitablemente estaría mediatizada por la comprensión propia de cada traductor.

Esto nos llevó a proponer una única traducción, concibiendo una práctica traductiva análoga a la reconstrucción lingüística² ${ }^{2}$.

\subsection{1. ¿Qué es una traducción reconstructiva?}

El discurso oral de Saussure desapareció para siempre y de los tres cursos de lingüística general sólo tenemos algunas notas preparatorias suyas y los cuadernos de sus estudiantes, que no siempre concuerdan entre sí. Por ejemplo, el nivel de lengua es muy variable: familiar y muy coloquial en unos estudiantes, culto escrito en otros, culto oral en otros más. ¿Cómo entender esta discrepancia en los niveles de lengua cuando no conocemos a ciencia cierta el estilo oral de Saussure frente a esos estudiantes? Es comprensible que sabiendo que son notas

2 La traducción al alemán d'Annette Kaudé de una parte del tercer curso de lingüística general (2006) fue el excelente modelo que nos ayudó a concebir este ejercicio. 
de un curso, el lector de los cuadernos de un único estudiante adjudique, por ejemplo, las expresiones cultas al profesor y las demás al estudiante mismo, según una interpretación subjetiva. Sin embargo, cuando se comparan las diferentes versiones de los estudiantes, se puede realizar una interpretación menos subjetiva; por ejemplo, si determinamos cuantas expresiones cultas y cuantas coloquiales anotaron espontáneamente todos los estudiantes, y cuáles se repiten, podemos plantear según este criterio cuantitativo qué parte del discurso correspondería de manera más verosímil al profesor y qué parte sería propia y singular de cada estudiante, siempre y cuando los estudiantes comparados no se hayan copiado entre sí.

Ahora bien, este tipo de operación, basada en la comparación de varias versiones de un mismo modelo, es justamente el fundamento del método reconstructivo en lingüística. Cabe precisar que ya se trató de reconstruir el discurso perdido de Saussure a partir de diferentes versiones de los estudiantes, como cuando Robert Godel publicó la Introducción del segundo curso (1957b). Ejemplar por su factura filológica, esta mezcla de varias fuentes creó sin embargo un sesgo importante ya que más adelante esta reconstrucción se llegó a citar como si fuera prácticamente un manuscrito de primera mano (Barthes, 1964). Se pudo tomar pues implícitamente este texto de Godel como el discurso original de Saussure, haciendo olvidar que ese discurso desapareció y no hay ninguna manera de recuperarlo.

Las reconstrucciones siempre han tenido este problema: si están bien hechas, se confunden con el objeto perdido que se trató de reconstruir, lo cual perturba sobremanera el rigor científico de toda disciplina histórica. Por ejemplo, a principios del siglo diecinueve, comparando el sánscrito con el latín y el griego, Franz Bopp pudo concebir lo que estas lenguas tenían en común y propuso su deducción como anterior a las lenguas comparadas, deducción que más tarde se llamó el indoeuropeo. Casi inmediatamente, el mismo método comparativo se utilizó con gran éxito para las demás lenguas europeas y el descubrimiento del llamado latín vulgar y del prototipo germánico confirmaron con testimonios existentes tanto la validez del método como su producto, a saber, la reconstrucción del indoeuropeo, del cual, sin embargo, no se conserva ningún documento.

El indoeuropeo, esta lengua reconstruida, es pues un cálculo y sólo eso, pero como las numerosas equivalencias en las que se basa son matemáticamente exactas, es un cálculo tan verosímil que se llegó a creer en la existencia de un pueblo que "tendría que haber hablado" esta lengua reconstruida. Del pueblo, rápidamente se pasó a la "raza indoeuropea", cuya existencia nunca se ha comprobado y de la que se duda cada vez más (Démoule, 2014). Al contrario, la validez de la reconstrucción de lengua nunca se ha puesto en duda, pero sólo como una abstracción retrospectiva y no como una lengua real que se hubiera hablado efectivamente. Toda reconstrucción es reductora, pues sólo consiste en algunos rasgos que la realidad que se reconstruye presentó en el pasado, precisamente los rasgos pertinentes según el punto de vista de dicha reconstrucción. La realidad pasada siempre presenta más rasgos, es necesariamente más rica. Un cálculo reconstructivo, aunque pueda ser "válido", jamás será entonces equivalente a la realidad pasada.

A nivel metodológico, la validez de una reconstrucción es primordial para las disciplinas humanas pues todas presentan una parte histórica $\mathrm{y}$ tienen que reconstruir en diferentes medidas. Ahora bien, las reconstrucciones de las disciplinas humanas son de una índole diferente de la de las reconstrucciones de las demás disciplinas.

En otros campos, en donde también se reconstruye (arqueología, criminología, geología, atribución de obras de arte, etc.), las deducciones se basan en relaciones causales verificables. Estas relaciones causales se repiten y se pueden observar idénticas en retrospección y en prospección. Por ejemplo, la trayectoria de una bala se puede determinar retrospectivamente, o sea que después de haberse disparado la bala se puede reconstruir su trayectoria a partir del punto de impacto. $Y$ si se toma el punto de partida reconstruido y se vuelve a disparar la bala en condiciones semejantes, se debería llegar 
prospectivamente al mismo punto de impacto. El punto de partida de la bala que se ha deducido en retrospección es verificable repitiendo el acto en prospección, y en este caso la retrospección certera equivale a la prospección.

En cambio, cuando se trata de reconstruir algo que no se rige por relaciones causales como los objetos de las disciplinas humanas (lingüística, historia, economía, sicoanálisis, antropología, geografía humana, etc.), la retrospección no es equivalente a la prospección. Por ejemplo, si tomamos el español lluvia y reconstruimos su origen llegaremos al latín pluvia; en cambio, si en prospección tomamos el latín pluvia y miramos qué dio, encontraremos tanto lluvia como pluie, choiva, pluja, pioggia, chuva, ploaie. No se puede afirmar entonces que haya habido una relación necesaria para que pluvia produjera lluvia. El punto de partida de lluvia que se ha deducido en retrospección no se puede verificar en prospección, y entonces una retrospección por muy válida que sea no equivale a la prospección.

En este caso de las relaciones únicamente temporales ( $x$ es simplemente anterior a $y$ ), en las cuales la retrospección no equivale a la prospección, y en las que no se puede demostrar que exista ningún vínculo causal ( $y$ no es "efecto necesario" de $x$ ), el factor cuantitativo se convierte en el único medio para alcanzar la verosimilitud, que no la veracidad, de una reconstrucción.

Sin embargo, este alto valor del factor cuantitativo es también un escollo teórico importante: con el método comparativo y teniendo un número suficiente de elementos que comparar, se puede llegar a una verosimilitud matemáticamente muy elevada, que introduce la confusión porque hace creer que también se puede tratar de relaciones causales ${ }^{3}$.

El grave problema que Saussure resolvió con el método que propone es pues el del rigor del estudio histórico en las disciplinas humanas. Aunque Saussure no se exprese en términos de relaciones causales y relaciones temporales, la diferencia entre estos dos tipos de relaciones fue establecida con base en la reflexión expuesta en el primer curso de lingüística general: analizando los cambios fonéticos, Saussure distingue claramente prospección y retrospección, demuestra que las relaciones de las lenguas no se pueden verificar en prospección, pues son únicamente temporales, lo que lo lleva a concebir un nuevo método de estudio que sólo es retrospectivo y que aplica a lo largo del curso, explicándolo cada vez con ejemplos pormenorizados que analiza en todos sus detalles.

Podemos vislumbrar la importancia de este método saussureano con sólo repasar los errores históricos de la lingüística del siglo diecinueve y las implicaciones sociales que tuvieron. Las consecuencias que las falacias históricas pueden engendrar se basan en estos tres errores teóricos fundamentales, que se cometieron, todos, con respecto a la reconstrucción del indoeuropeo:

1. Se supuso que la lengua reconstruida indoeuropea debió haberse hablado tal cual, que era equivalente a una lengua muerta: error de pensar que, en lingüística, retrospección equivale a prospección. El indoeuropeo no puede ser sino un cálculo retrospectivo, y por tanto reductor.

2. Al confundir una reconstrucción con una lengua muerta se creyó que tenía que haber existido un pueblo que también tenía que haber compartido, prospectivamente, una misma herencia biológica: error de confundir la relación únicamente temporal con la relación causal.

3. Esta "raza", fruto de la combinación de los dos errores anteriores, recibió los adjetivos que se utilizaron para la lengua reconstruida, la cual, al no ser sino una abstracción, era completamente "lógica" y "perfecta": error de confundir la abstracción reconstruida con la realidad desaparecida.

Círculo vicioso, cada error se apoyaba en los demás.

3 En medicina, por ejemplo, se habla en este caso no de causalidad sino de "factores de riesgo", es decir de porcentajes de "probabilidades de causalidad", noción que puede resultar supremamente falaz (Mejía Quijano, Germond et Ansermet, 2006; Mejía Quijano, 2012b). 
Ahora bien, en estos dos últimos siglos se vieron las consecuencias de cómo esta imaginaria noción de "raza perfecta indoeuropea" aprovechó la validez de la reconstrucción lingüística, parasitándola por completo: primero se adjudicó un aura de cientificidad que no le correspondía y que fue utilizada por regímenes totalitarios en sus afanes destructores, y después de la segunda guerra mundial, al constatarse los efectos nefastos de esa falacia, hizo desconfiar del rigor de la reconstrucción lingüística, haciendo menospreciar los estudios evolutivos de la lengua.

Estos errores teóricos se hubieran podido evitar simplemente con la distinción entre relaciones temporales y relaciones causales. Por ejemplo, y para volver a las publicaciones de los cursos, al comparar las versiones de Albert Riedlinger, Léopold Gautier y François Bouchardy, pero dando sólo la versión reconstruida de la introducción al segundo curso (1957b), aunque nunca pretendió suplantar a Saussure, Robert Godel también dio lugar a esta ilusión de óptica, que hace que una excelente reconstrucción de algo se confunda con ese algo desaparecido.

En cambio, la edición crítica del Curso de Rudolf Engler (1968-1974) no presenta este inconveniente, pues reproduce varias versiones de un mismo original desaparecido. La trampa de las reconstrucciones a partir de relaciones únicamente temporales, en la que se puede caer creyendo que se encontró la realidad desaparecida, se evita pues explicitando los elementos que se comparan para reconstruir, porque entonces se deja la libertad al lector para que sea él mismo quien calcule su propia reconstrucción del discurso original, sin imponer una visión específica. La edición diagramática de Engler, texto fundamental en este sentido, no tuvo, sin embargo, un amplio impacto fuera de los especialistas, pues exige del lector este trabajo de reconstrucción que no sólo es arduo, sino que requiere conocimientos lingüísticos e históricos específicos.

Fue deseando proporcionarle al público académico amplio un texto con el que pudiera acceder en español a los manuscritos de primera mano, sin adolecer de los sesgos interpretativos mencionados, que pensamos en un tipo particular de traducción, que se podría llamar "reconstructiva": una traducción en la que, comparando las versiones en francés de los estudiantes, se tradujera en español lo que el profesor "pudo haber dicho". No tradujimos entonces los manuscritos en sí, sino lo que en ellos vimos del discurso desaparecido de Saussure.

Este ejercicio de reconstrucción combinada con la traducción presenta una ventaja importante: una "traducción reconstructiva" nunca podrá confundirse con su original, por muy lograda que esté, pues la presencia del traductor, su realidad actual, su intromisión está explícita en la misma diferencia de lengua. Para nuestro caso, nadie se podría imaginar que un texto en español, por muy verosímil que parezca, sea el "discurso de Saussure", ya que no será sino una traducción, la cual se acepta naturalmente como diferente del original, pues toda traducción contiene la parte de interpretación del traductor.

Proponemos pues al lector hispanohablante una traducción comprensible, fácil de leer y rigurosa, que lo puede introducir en el salón de clase de Ferdinand de Saussure en 1907.

El lector francohablante tendrá un acceso privilegiado a los dos manuscritos primarios que se conservan y comparándolos entre sí podrá también sentarse en primera fila frente al maestro ginebrino.

El lector bilingüe francohispano, además de escuchar a los estudiantes y al profesor, podrá también considerar el trabajo reconstructivo que realizó el traductor.

\section{3. ¿Cómo se eligieron los manuscritos?}

En septiembre de 1906, al retirarse el titular de la cátedra de Lingüística, Joseph Wertheimer, quien había dado esta asignatura durante más de 20 años, la Facultad de Letras y Ciencias sociales de la universidad de Ginebra en Suiza, le pidió a Ferdinand de Saussure que además de los suyos, también dictara este curso, añadiéndole dos horas más a su plan de trabajo. Saussure aceptó lo que para él significaba un gran desafío, ya que él sólo había enseñado idiomas particulares, pero pidió un tiempo 
prudencial para preparar este nuevo curso que, según los Archivos de la Universidad de Ginebra, sólo empezó el 16 de enero de 1907 y terminó el 2 de julio del mismo año. Al parecer, por problemas de solapamiento entre dos cursos hasta finalizar el semestre de invierno Saussure sólo dictó una clase por semana, el miércoles a las 10am en la sala 46 del edificio de los Bastiones. En cambio, según el programa de los cursos, en el semestre de verano entre el 8 de abril y el 2 de julio, se dictaron dos clases a la semana, los lunes y los martes a las 10am en las salas 46 y 47 respectivamente.

La licencia de letras de la universidad de Ginebra no tenía gran prestigio en ese entonces y eran muy pocos los estudiantes que se inscribían. No más de cuatro estudiantes seguían los cursos que dictaba habitualmente Saussure, de sánscrito y de lenguas germánicas. Sin embargo, para este nuevo curso de lingüística general hubo 12 estudiantes inscritos, de los cuales cuatro ginebrinos, un alemán, dos búlgaros, dos rusos, un escocés, un italiano y un francés. De éstos, sólo siete estaban inscritos en la licencia de letras, los demás eran de ciencias sociales, y según las inscripciones sólo tres estudiantes siguieron el curso ambos semestres: Albert Riedlinger, Louis Caille y Victor Martin. Este último estudiante llegaría a ser luego rector de la universidad de Ginebra, pero si él conservó sus notas, no se han encontrado hasta el momento.

Nuestra traducción reconstructiva está basada entonces en las notas tomadas durante el curso por Albert Riedlinger y por Louis Caille, que son las únicas completas y conservadas. Estos manuscritos son muy particulares y exigen una presentación pormenorizada.

\subsubsection{Cuadernos de Louis Caille}

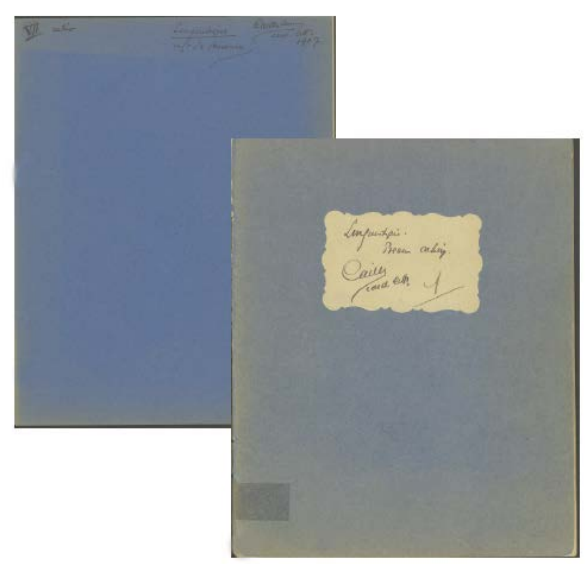

BGE: Cours universitaires 762

Descripción física: Siete cuadernos escolares con portada azul de $17.5 \mathrm{~cm} \times 22 \mathrm{~cm}$, con casi todas las páginas escritas (sólo el último cuaderno tiene al final hojas en blanco), a lápiz en su mayoría aunque también algunas lecciones están escritas en tinta; algunas páginas están sueltas por haberse despegado y en ciertos lugares algunas páginas parecen haber sido arrancadas, aunque el texto no presenta ningún vacío.

Las páginas están escritas en taquigrafía con amplias márgenes exteriores laterales en las que, siempre con tinta, se escribieron frases cortas en caracteres latinos, que resumen lo dicho en la taquigrafía: a veces se trata sólo de un simple "título" o idea central del párrafo correspondiente. Salvo excepción, en estos "resúmenes" no hay ninguna idea diferente de las anotadas en la taquigrafía, e incluso la mayoría de los nombres propios están escritos con los mismos errores de ortografía que los de la escritura latina del texto del autor.

A pesar de presentar variaciones, la escritura de estos caracteres latinos presenta cierta homogeneidad de estilo en la mayoría de las lecciones y puede corresponder a la escritura de una misma persona, salvo rara excepción ${ }^{4}$. Si

4 Hay una página en donde se puede ver una escritura que parece claramente la de otra persona. Esta excepción corresponde a la lección sobre los cambios analógicos, la cual presenta más anotaciones que las demás lecciones pues fue muy trabajada ulteriormente por Albert Riedlinger. En el folio 1 del manuscrito BGE: Ms. fr. 9168-3, Riedlinger enumera ciertas lecciones de la taquigrafía de Caille que él parece haber leído con detenimiento y que son precisamente las que presentan anotaciones en la margen, al parecer, escritas por terceros. 
se comparan además con los caracteres latinos que se incluyen en el texto de taquigrafía, es muy verosímil que la mayoría de los resúmenes hayan sido escritos por el mismo Caille y pueden entonces corresponder a los diferentes momentos en los que este estudiante repasó la materia del curso preparando su examen, como era además usual para los estudiantes de la época, y como así lo hiciera, por ejemplo, Emile Constantin con sus cuadernos del Tercer curso, que presentan resúmenes semejantes. Muy probablemente, ése también era el método de estudio de Caille, quien al escribir la taquigrafía respetó esas grandes márgenes en todos los cuadernos, o sea que preveía utilizarlas desde el principio.

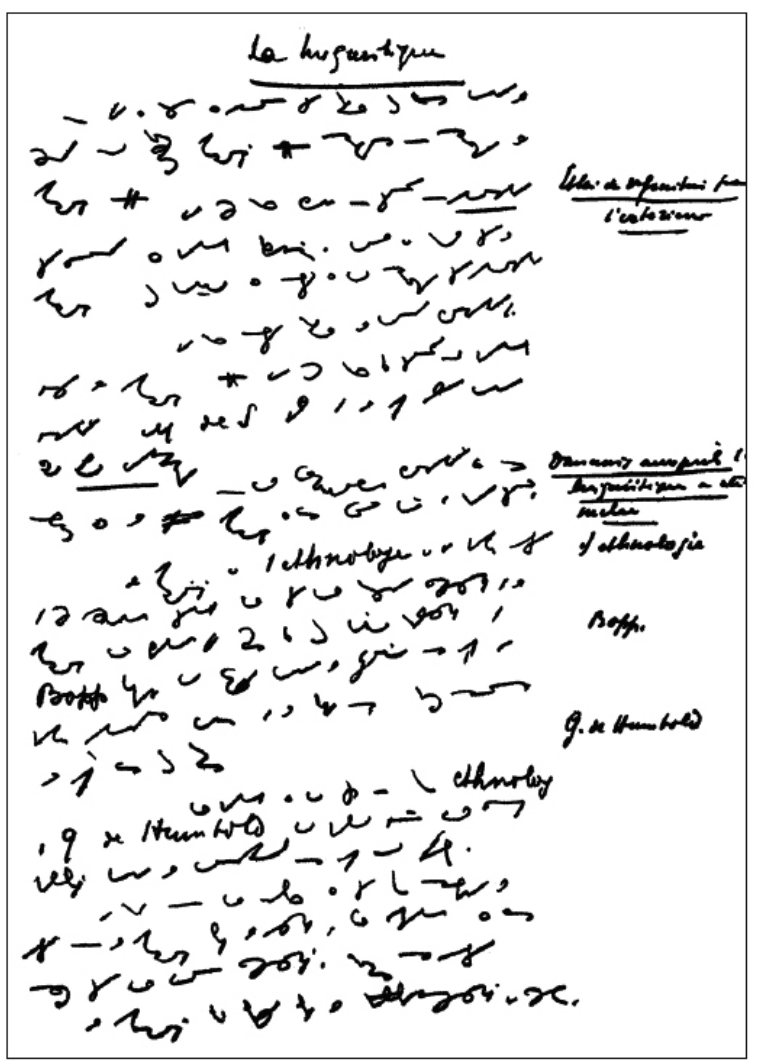

Cuadernos de Louis Caille, p. 1

BGE: Cours universitaires 762

A pesar de que suponemos el mismo autor para la taquigrafía y los caracteres latinos, en nuestra edición, así como lo hicimos en la de los cuadernos de Emile Constantin (Saussure, 2006a), no tomamos en cuenta estos resúmenes en caracteres latinos ya que, no sólo repiten lo dicho en la taquigrafía sino que, interpretados como un momento ulterior de estudio, no pertenecerían stricto sensu al documento de "primera mano", que para nosotros corresponde a lo escrito en el momento mismo del curso.

Ordenados, con pocos errores, sólo tachones insignificantes, frases redactadas en su totalidad aunque con un estilo algo escueto, estos cuadernos en taquigrafía constituyen el manuscrito más fidedigno que nos transmite la argumentación lingüística de Saussure.

La transcripción fue realizada por Alexánder Pérez Zapata y Claudia Mejía Quijano

\subsection{Notas de Albert Riedlinger}

De este estudiante existen en la actualidad dos juegos de notas, de contenido algo diferente $\mathrm{y}$ escritos en dos momentos alejados en el tiempo. Comencemos con las notas que fueron descubiertas recientemente y que al parecer nadie conoció en el siglo veinte.

\section{Primer juego de notas, tomadas durante el curso}

Estos manuscritos fueron donados en diciembre de 2010, por los descendientes de Albert Riedlinger, luego de haber sido contactados por Barbara Roth, conservadora del Departamento de manuscritos de la Biblioteca de Ginebra, y fueron catalogados con el código BGE: Ms. fr. 9168-3, f. 2-215.

Descripción física: 107 folios sueltos, la mayoría de aproximadamente $17 \mathrm{~cm} \times 22 \mathrm{~cm}$, en diferentes tipos de papel, algunos escritos a lápiz, pero sobre todo en tinta negra, la mayoría sin márgenes pero también con algunos espacios dejados en blanco en el texto, al parecer voluntariamente.

Estas notas presentan añadidos, correcciones, tachones; están redactadas pero de manera bastante desigual por la rapidez de la escritura: el estudiante no termina algunas frases, comete bastantes errores de ortografía, a menudo las abreviaciones se multiplican, la expresión se vuelve elíptica aunque no alcanza a ser telegráfica e incluso las palabras se pegan entre sí. El estudiante no parece 
realizar un trabajo de asimilación del sentido del discurso, copia todo lo que alcanza a captar, como sin ninguna discriminación consciente. El uso del espacio de la página también muestra la improvisación con un orden muy sui generis que denota la necesidad de no desperdiciar el papel y de copiar lo que más podía del discurso escuchado.

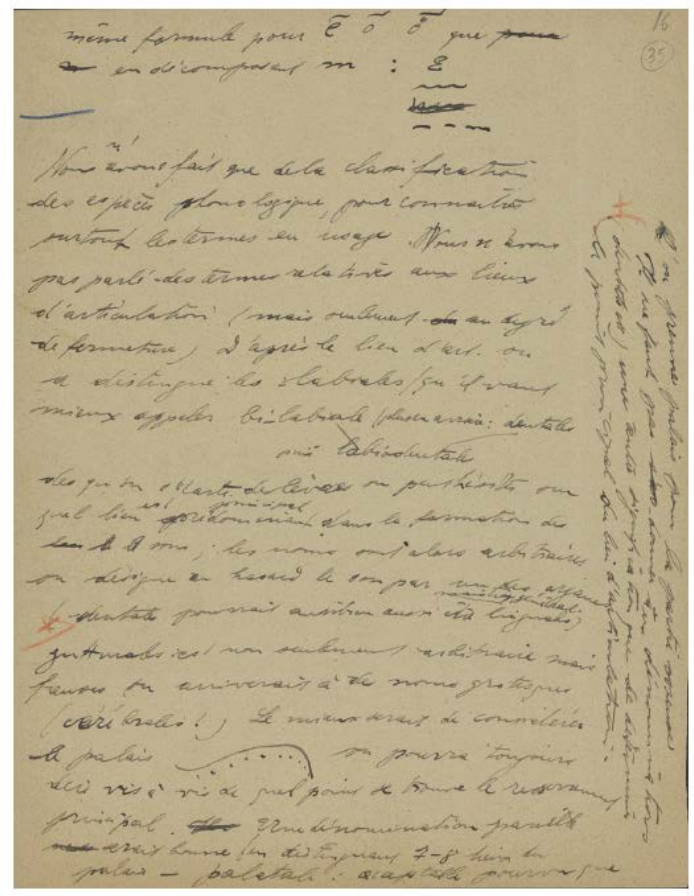

Notas de Albert Riedlinger, p. 35 BGE: Ms. fr. 9168-3

\section{Identificación del manuscrito Ms. fr. 9168-3}

En el catálogo de la BGE, este manuscrito está identificado como notas de un curso de lingüística general de F. de Saussure, pero no hay ninguna identificación cronológica. Entre los manuscritos donados en el 2010 por los descendientes de Riedlinger, figuran además las notas originales de otro curso, el de Gramática histórica del griego y del latín (BGE:
Ms.fr. 9168-1) que también fue pasado a limpio pues un segundo juego se conserva asimismo en la Biblioteca de Ginebra (BGE: Cours universitaires 824). Lo que corrobora la idea de que Riedlinger había donado en los años 1960 los cuadernos pasados a limpio, pero no se había desecho de las notas originales, que conservó cuidadosamente. El contenido y la materialidad de los manuscritos, la redacción que presentan - típica de la toma de notas rápida de un curso, y la comparación con las notas en taquigrafía de Caille demuestran que el documento BGE: Ms. fr. 9168-3 corresponde a las notas tomadas por Albert Riedlinger durante el primer curso de lingüística general, y consigna directamente el discurso del profesor.

Como manuscrito de primera mano, e inédito al comenzar nuestro proyecto en otoño de 2012, elegimos transcribir y publicar únicamente este juego de notas.

\section{La transcripción fue realizada por Daniel Jaramillo Giraldo y Claudia Mejía Quijano}

Cabe aclarar que el folio № 1 de este código no corresponde al mismo documento, pues es una anotación que se refiere al contenido de los cuadernos de Louis Caille. Sin embargo, cuando enumeraron el conjunto de folios incluyeron este primer folio por error: esta clasificación defectuosa proviene de la identificación de quien enumeró el manuscrito, autor asimismo de un artículo reciente (Vincent, 2014), en el cual este investigador resume su tesis de doctorado sostenida en 2013. Según ese resumen, en la tesis se pretende que este manuscrito ${ }^{5}$ sería un texto ulterior al curso, además de otras afirmaciones que no concuerdan con nuestros hallazgos.

5 Habría que aclarar si F. Vincent sí se refiere al mismo manuscrito que nosotros: en la bibliografía de su artículo menciona el código BGE: Ms. fr. 9168-4 y afirma tres veces que D. Gambarara descubrió el manuscrito en octubre de 2011. Ahora bien, en el código BGE: Ms. fr. 9168-4 no se encuentran tantas notas de curso, sino sobre todo cartas. Y todo el código BGE: Ms. fr. 9168 corresponde a los manuscritos encontrados por Barbara Roth. Sin embargo, F. Vincent tambien precisa la clasificación provisional que la Biblioteca de Ginebra le dio cuando los descendientes de Riedlinger lo donaron (2010/34/3) y además menciona el número de folios. Ahora bien, en el código BGE: Ms.fr. 9168 ningún otro manuscrito podría corresponder a ese número de folios sino el BGE: Ms. fr. 9168-3 que antes se catalogó con la entrada 2010/34/3, por lo que suponemos que F. Vincent sí se refiere al manuscrito del que tratamos aquí. 
Explicitamos a continuación las razones de nuestra discrepancia con al menos cuatro de las conjeturas de F. Vincent, que atañen directamente a la identificación del manuscrito.

1) F. Vincent califica este manuscrito de "intermediario", pues según él, no sólo es la base de los segundos cuadernos de Riedlinger, punto en el que concordamos, sino que sobre todo correspondería a la transcripción mejorada de la taquigrafía de Caille. Si bien está claro que tanto este manuscrito como los cuadernos de Caille se refieren a un mismo discurso, el contenido que se retuvo y la manera de hacerlo en ambas versiones son tan diferentes, los puntos comunes son tan tenues que no entendemos cómo se puede llegar a esa conclusión. Todo lo contrario, partiendo de la lectura de las dos versiones por separado, está claro que nos encontramos frente a dos versiones distintas y contemporáneas de un mismo original ausente; la versión de Riedlinger no es posterior a la versión de Caille.

2) Oponiéndose a lo dicho por el mismo Riedlinger, a lo establecido por Godel y Engler, $\mathrm{y}$ a lo verificado por todos los saussureanos que han estudiado los manuscritos sobre los cursos de lingüística general de Saussure, F. Vincent duda que Riedlinger sí hubiera asistido a ese curso, lo que concordaría con su afirmación de que Caille habría sido el único estudiante que hubiera tomado notas en ese curso. Ahora bien, la carta de Riedlinger a Saussure que publicamos más adelante, descubierta en 2013 y la respuesta de éste a Riedlinger, publicada en la correspondencia de Saussure (2014, p. 553), corroboran lo que ya se había establecido muy bien: Riedlinger no sólo asistió a ese curso sino que sí tomó notas durante las lecciones.

3) F. Vincent afirma que el manuscrito habría sido escrito por ambos estudiantes. Esta afirmación no corresponde a la materialidad misma del documento: desde el principio hasta la última página no se encuentra sino una sola y misma letra, la de Riedlinger. Además, la redacción y el estilo distan considerablemente de los de Caille $\mathrm{y}$, en cambio, corresponden claramente a los de Albert Riedlinger.

4) F. Vincent propone que el manuscrito habría sido escrito después del curso y no durante el curso.
Por el contenido mismo y las características materiales de estas notas - por ejemplo las frases incompletas, las palabras pegadas, la inclinación de los renglones, la distribución espacial del contenido en la hoja, los múltiples indicios de improvisación (errores de ortografía y de concordancias, cambios sintácticos aleatorios, etc.), es muy poco probable que este documento no haya sido escrito "a la carrera". El simple estado de las notas corresponde a ojos vistas a la redacción típica de la toma de notas rápida de un curso, y no a una verdadera "redacción". Es de anotar que el mismo F. Vincent señala además que los grupos de diferentes papeles utilizados por Riedlinger hacen pensar que el texto se escribió en diferentes sesiones.

\section{Segundo juego de notas, "pasadas en limpio"}

Las únicas notas de Albert Riedlinger que se conocieron en el siglo veinte corresponden a los cuadernos que él le entregó a Albert Sechehaye y a Charles Bally para la redacción del Curso. Estas notas son diferentes del primer juego, tanto en forma como en contenido. Muy bien redactadas, aunque poseen el mismo esqueleto, contienen ideas e informaciones que no están en el primer juego, e incluyen asimismo las notas de una lección a la que, al parecer, Riedlinger no asistió.

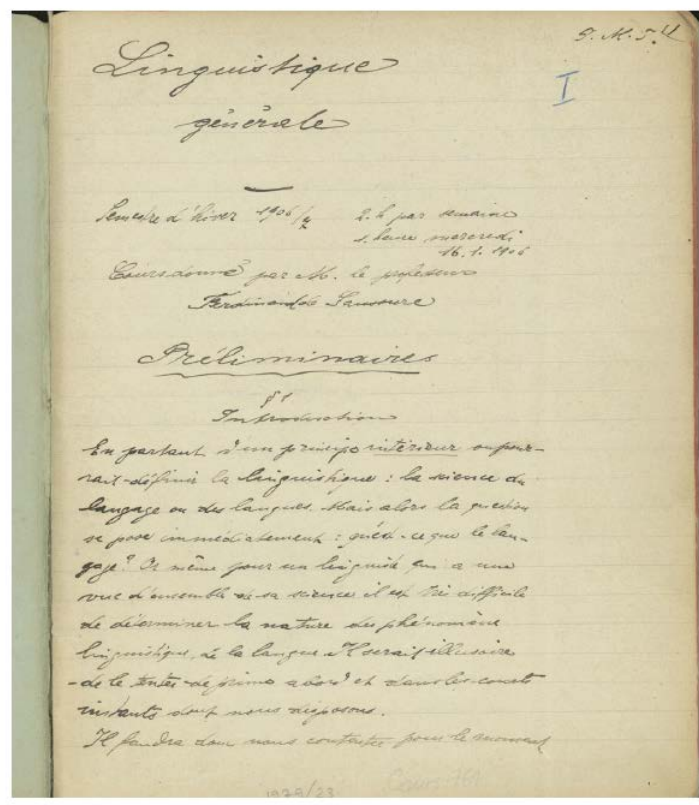

Cuadernos de Albert Riedlinger, p. 1 BGE: Cours universitaires 761 
Estos cuadernos tan completos y totalmente redactados constituyeron la única fuente del Curso con respecto a la materia del primer curso, ya que a pesar de que se conocía la existencia de los cuadernos en taquigrafía de Louis Caille, se sabía que Riedlinger había utilizado estos últimos cuando pasó en limpio los suyos. Por consiguiente, se suponía que sus cuadernos ya "contenían" la información que había anotado Caille, aunque por supuesto no se podía apreciar en qué medida ni cómo la había utilizado Riedlinger.

Se creía además que, como era lo usual, Riedlinger había pasado en limpio sus cuadernos durante el curso mismo, o al menos al finalizar el curso, con miras a presentar el examen correspondiente. Sin embargo, Riedlinger, quien acababa de empezar sus estudios universitarios en 1906, no presentó el examen al finalizar el año académico pues era un examen de licencia, sino que repitió el curso de lingüística general dos años después, y sólo presentó el examen correspondiente al acabar sus estudios, en octubre de $1911^{6}$, o sea cuatro años después de haber seguido el primer curso.

Entonces, ¿cuándo redactó Riedlinger los segundos cuadernos del primer curso?

Como fecha post quem sería verosímil pensar en el final del curso, julio de 1907, pero sólo tenemos seguridad de una fecha ante quem: en una carta a Saussure, escrita el 20 de diciembre de 1911, Riedlinger le asegura que tiene a la disposición de su maestro los cuadernos pasados en limpio de todos los cursos de Saussure a los que asistió, cuya lista establece y en la que figuran los dos cursos de lingüística general:
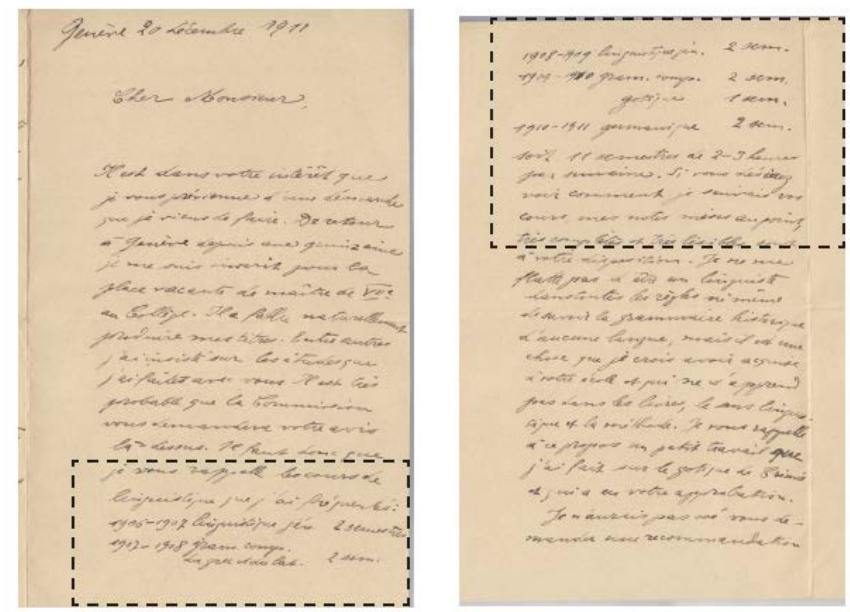

Carta de Albert Riedlinger a Ferdinand de Saussure, manuscrito privado conservado en el Castillo de Vufflens ${ }^{7}$.

"Me permito entonces recordarle los cursos de lingüística a los que asistí:

1906-1907 Lingüística general 2 semestres

1907-1908 Gramática comparada 2 semestres del griego y del latín

1908-1909 Lingüística general 2 semestres

1909-1910 Gramática comparada 2 semestres Gótico 1 semestre

1910-1911 Germánico 2 semestres

es decir 11 semestres de 2-3 horas por semana. Si desea ver cómo seguía yo sus cursos, tengo a su disposición mis notas pasadas a limpio, muy completas y muy legibles".

El segundo juego de notas de Riedlinger fue publicado parcialmente por Rudolf Engler en su edición crítica del Curso en 1968-1974, aunque según el orden de aparición de las ideas de ese libro, lo que no permitió que se apreciara el desarrollo efectivo del curso. Años más tarde, Eusuke Komatsu retomó idéntica la edición de Engler pero publicándola en el orden de las

6 Según el registro de los Archivos de la Universidad de Ginebra.

7 Catalogado en Mejía Quijano, 2015. Esta carta tambien se menciona en el artículo "La part de l'élève dans la voix du maître", Beiträge zur Geschichte der Sprachwissenschaft, Münster: Nodus Publikationen. Vol 26-2, 2016. 
lecciones: una vez en Japón (1993a) y una segunda edición, bilingüe francés-inglés, en Oxford con el traductor Georges Wolff (1996). Esta última edición, aunque siguió siendo incompleta, es menos lacunaria pues incorpora la transcripción de la mayoría de las partes faltantes en la edición de Engler, salvo una docena de páginas al final del curso.

Para nuestra edición, hemos dejado de lado estos manuscritos de segunda mano, aunque sí los hemos consultado, pues aportan al menos lo que Albert Riedlinger retuvo en conjunto de los dos cursos dictados por Saussure.

\section{5. ¿Cómo se realizó la traducción reconstructiva?}

De manera teórica es difícil explicar adecuadamente cómo se realizó esta traducción, pues habría que tener en cuenta muchas variables, pero unos cuantos ejemplos específicos permitirán que se vislumbre la operación traductiva que realizamos. Prácticamente, se iba leyendo cada unidad de sentido en las dos versiones y se trataba de concebir lo que Ferdinand de Saussure pudo haber expresado justo en esa lección, frente a sus estudiantes, en el salón de clase. Se trató pues de concretizar lo mejor posible el sentido de lo dicho, no solo con respecto al contenido lingüístico sino también, e incluso primero, frente al contexto específico de la clase misma, que fue el marco en el que las oraciones anotadas tomaron un sentido preciso para cada estudiante.

Según este marco pedagógico, al discurso de Saussure tal como lo registró Caille, se le sumó a veces el que Riedlinger anotó, pero otras veces se escogió entre ambos, e incluso se llegaron a mezclar de tal manera que la idea traducida resultó completamente nueva. La traducción no corresponde entonces estrictamente ni a un manuscrito ni al otro, sino al "producto mental" de ambos, que desde luego se realizó según la horma de nuestra propia interpretación del estilo y pensamiento que, creemos, corresponden al discurso que hubiera podido enunciar Saussure en 1907.
Recalquemos entonces que la presente traducción es bastante peculiar, pues no tiene propiamente original y ese original ausente tampoco tiene un verdadero autor. $\mathrm{O}$ mejor dicho, para nuestra traducción existen dos originales y tres autores. Por esto, fuera de analizar pormenorizadamente los dos originales, tuvimos que tener en cuenta a los tres autores $\mathrm{y}$, analizándolos, distinguir entre el discurso perdido del profesor y la comprensión de cada estudiante.

\subsubsection{El hablar del profesor}

Según varios testimonios de sus compañeros (Amé Pictet, Francis Decrue, Alfred Favre), colegas (Ernest Muret, Antoine Meillet) y estudiantes (Georges Guiyesse, Georges Dottin, Albert Sechehaye, Léopold Gautier, Paul F. Regard) el discurso de Saussure poseía un estilo muy sui generis: culto y muy preciso pero, a pesar de esto, sencillo y sin afectación. Saussure hacía entender conceptos complicados a sus oyentes, utilizando imágenes claras y expresivas con palabras corrientes que le permitían a su auditorio apasionarse por cualquier tema, aun el más árido para ellos. Al hablar en situaciones cotidianas, Saussure ya presentaba esta particularidad desde muy joven, comolo cuenta en el diario de juventud su amigo Amé Pictet, interesado únicamente en las ciencias naturales y quien más adelante se convirtiera en profesor de química:

De Saussure se met à nous expliquer à Go et à moi des étymologies sanscrites, comme quoi sanscrit, grec et latin sont fils d'un même père, l'indogermain et frères de presque toutes les autres langues de l'Europe, comme quoi c'est cet indogermain De Saussure se met à nous expliquer à Go et à moi des étymologies sanscrites, comme quoi sanscrit, grec et latin sont fils d'un même père, l'indogermain et frères de presque toutes les autres langues de l'Europe, comme quoi c'est cet indogermain qu'on tâche de reconstituer synthétiquement quoique on en ait aucun document quelconque. Le tout appuyé de nombreux exemples jusqu'à 1 heure du matin. Ce brave de Saussure se lançait à travers ses mots barbares; on voyait qu'il était dans son élément et le plus comique de l'affaire, c'est que j'ai parfaitement compris et que je me suis mis à avouer, presque, que 
ces études philologiques pouvaient avoir une certaine utilité.

26 mars 2 heures du matin.

De Saussure se puso a explicarnos a Go y a mi etimologías sanscritas, cómo el sanscrito el griego y el latín son hijos de un mismo padre, el indogermánico y hermanos de casi todos los demás idiomas de Europa, y cómo este indogermánico es el que tratan de reconstituir sintéticamente, aunque no se posea ningún documento. Todo eso sustentándose en numerosos ejemplos hasta la una de la mañana. Este excelente de Saussure nos mostraba las palabras más extrañas, estaba claro que se sentía en su elemento y lo más cómico de todo, es que entendí perfectamente y llegué casi hasta a aceptar que estos estudios filológicos sí pudieran tener alguna utilidad.

26 de marzo, 2 am. (BGE: Ms. fr. 1599/5 f. 26).

Los testimonios ulteriores sobre Saussure mencionan a menudo su parole, es decir su manera de hablar. En esta palabra francesa de parole confluyen en especial dos significaciones: por un lado, el encadenamiento de las palabras y de las ideas en el discurso, y, por el otro, la pronunciación, la manera de articular los sonidos de las palabras. A este respecto, cabe mencionar que Saussure era aristócrata por parte materna, su linaje comprendía una rama de la realeza inglesa, y otra de la aristocracia prusiana. Ahora bien, este ser aristocrático de Saussure, que desde un punto de vista lingüístico no quiere decir absolutamente nada para nuestra época, a finales del siglo diecinueve en el mundo francohablante, era supremamente importante con respecto a la parole: los aristócratas en el antiguo régimen francés eran otra "raza" a la que le importaba distinguirse de los "plebeyos" con múltiples marcas, entre las cuales la más visible, la más espontánea, la que más se enlazaba con el pretendido derecho natural del aristócrata para distanciarse de los demás, era una pronunciación específica que se reconocía con facilidad. Esta pronunciación dio lugar en el siglo veinte a parodias, pero ya no es común recordarla tal cual, salvo como burla o burdo remedo nuevorico de lo que fuera la élite, la clase dirigente de los abandonados imperios europeos.

Por falta de grabaciones, existen pocos estudios fonológicos sobre la pronunciación aristocrática francesa del siglo diecinueve, tampoco sobre lo que pudo haber sido esa pronunciación en la Suiza francesa, y menos aún en un ginebrino culturalmente mestizo (Prusia-Francia) como lo fueraSaussure. Pero de loque sí queda rastro es dela admiración que ese hablar aristocrático despertaba en sus contemporáneos, que lo describían como "claridad y elegancias soberanas", "exquisita distinción y fineza”, "gracia aristocrática”.

Quizás fuera precisamente el contraste entre ese hablar aristocrático con su prosodiasintaxis característica y una lengua límpida y sencilla lo que causaba tal admiración. En una carta dirigida a la viuda de Saussure, un antiguo estudiante parisino, Georges Dottin, quien luego se convirtiera en renombrado celtista, fuera Decano de la Facultad de letras de la Universidad de Rennes y Corresponsal del Instituto de Francia, describe así los sentimientos que el profesor inspiraba en sus estudiantes con su discurso:

Je revois son élégante silhouette et sa main fine écrivant au tableau noir et effaçant les mots écrits sans qu'un atome de craie vînt poudrer ses habits. La petite salle sombre de l'Ecole des Hautes Études où les livres empiétaient sur les hommes était toute éclairée de sa lumière et je me souviens que Meillet un jour se penchant vers moi me dit «N'est-ce pas que Saussure est comme un dieu?». Et je me rends bien compte que ce n'est pas un de ces mirages comme on en voit à mon âge, quand on évoque les hommes ou les choses qui ont tenu une place dans la jeunesse, mais c'est la mémoire précise de l'action et de l'emprise que votre mari a eu sur moi .

Vuelvo a ver su elegante silueta y su delicada mano escribiendo en el tablero y borrando las palabras que había escrito con tanto cuidado que ni un átomo de tiza se le posaba en el traje. Su lucidez iluminaba la oscura salita de la

8 Carta catalogada en Mejía Quijano, 2015. 
Escuela de Altos Estudios en la que los libros rivalizaban por el sitio con los hombres, y me acuerdo cómo un día Meillet, inclinándose hacia mí, me dijo: "¿No te parece que Saussure es como un dios?". Y tengo muy claro que no se trata de uno de esos espejismos tan comunes a mi edad cuando se piensa en los hombres o en las cosas que fueron importantes en la juventud, sino que es el recuerdo exacto de la acción y de la influencia que su marido ejerció sobre mí.

Ese dios que veía en Saussure Antoine Meillet, quien luego se convirtiera en el lingüista francés más importante en la primera mitad del siglo veinte, no era Poseidón ni Dionisos, por supuesto, ¡sino Apolo! Para los discípulos de Michel Bréal y Gaston Paris en la Escuela de Altos Estudios en Paris, la pronunciación aristocrática de Saussure connotaba el logos griego, el genio intelectual y la cultura en su máxima expresión. Asociada con su equivalente escrito de la sintaxis, esta manera de hablar aristocrática determina en buena parte la extrema singularidad del hablante que fuera Saussure, y bien podría haber sido ésa una de las razones de los variados estilos que presentan los cuadernos de los estudiantes de sus cursos.

En particular, la contradicción estilística entre los estudiantes de 1907 es de entrada muy clara: el estilo del profesor en los cuadernos de Louis Caille es simple y conciso, el estudiante anota a menudo expresiones familiares, palabras coloquiales, giros orales. En cambio, en las notas de Albert Riedlinger encontramos expresiones más elaboradas, maneras de decir más cultas, algunos giros rebuscados, otros más corrientes, pero todos evocan "erudición".

Desde luego, cada estudiante le imprime a sus cuadernos su propio saber lingüístico. Si observamos todos los cuadernos que poseemos de los estudiantes que asistieron a los cursos de lingüística general de Saussure, podemos constatar muchos estilos diferentes, cada uno acorde más con el estudiante mismo que con el estilo del discurso propio de Saussure, que conocemos por escrito gracias a las notas autógrafas, preparatorias de varios cursos. No hay sino que comparar los cuadernos del segundo curso de Charles Patois, un poco ingenuos, con los sintéticos y críticos de Léopold Gautier, ya lingüista diplomado, o los del muy ecuánime pero sensible Emile Constantin con los del alegre y muy jovencito Francis Joseph del tercer curso, para ver cómo cada estudiante estampa su modo de ver, y hasta de ser, en las palabras y giros escogidos (Engler, 1968-1974).

Sin embargo, dos rasgos que descubrimos en filigrana en los cuadernos de todos los estudiantes, son específicos del estilo propio de Saussure, a saber la sencillez de las palabras (salvo desde luego cuando se trata de términos lingüísticos) y la claridad de las ideas expuestas, por muy complejas que éstas fueran.

¿Por qué entonces encontramos esta gran diferencia con respecto al nivel de lengua entre Caille y Riedlinger?

Desde un punto de vista semiológico, el nivel de lengua de las palabras que se utilizan en un discurso se puede vincular con la identidad de los participantes del acto de comunicación: es raro utilizar un nivel culto cuando uno habla con sus familiares, y existe un efecto evidente si se utiliza un nivel vulgar cuando uno habla con extraños, o con gente mayor. Pero el nivel de lengua, justamente porque corresponde a la identidad de los interlocutores, puede también ser visto como indicio de jerarquía social, y entra entonces como "norma" en el juego de poder socio-cultural que a menudo parasita la comunicación.

¿Cuál era el nivel de lengua de las palabras que el profesor utilizaba en su curso... profesor quien era asimismo un aristócrata ginebrino y se dirigía a jóvenes de varios medios socioculturales?

Si nos fiamos de los cuadernos de Caille, que contienen un vocabulario muy coloquial, podríamos pretender que, en el momento mismo de hablar frente a sus estudiantes, Saussure cambiaba su nivel de lengua con el fin de llegar mejor al auditorio presente en el curso, $\mathrm{y}$, precisamente en este primer curso, la mayoría de los asistentes no eran de habla nativa francesa, ni versados literatos. Es cierto que Saussure 
preparaba minuciosamente lo que quería decir, pero sólo en el momento de decirlo, decidía cuáles palabras transmitirían su pensamiento, como bien lo señaló Antoine Meillet en 1913:

Les enseignements particuliers que l'étudiant recevait de F. de Saussure avaient une valeur générale, ils préparaient à travailler et formaient l'esprit; ses formules et ses définitions se fixaient dans la mémoire comme des guides et des modèles.

Et il faisait aimer et sentir cette science qu'il enseignait; sa pensée de poète donnait souventà son exposé une forme imagée qu' on ne pouvait plus oublier. Derrière le détail qu'il indiquait, on devinait tout un monde d'idées générales et d'impressions; d'ailleurs il semblait n'apporter jamais à son cours une vérité toute faite; il avait soigneusement préparé tout ce qu'il avait à dire, mais il ne donnait à ses idées un aspect définitif qu'en parlant; et il arrêtait sa forme au moment même où il s'exprimait; l'auditeur était suspendu à cette pensée en formation qui se créait encore devant lui et qui, au moment même où elle se formulait de la manière la plus rigoureuse et la plus saisissante, laissait attendre une formule plus précise et plus saisissante encore. Sa personne faisait aimer sa science; on s'étonnait de voir cet œil bleu plein de mystère apercevoir la réalité avec une si rigoureuse exactitude; sa voix harmonieuse et voilée ôtait aux faits grammaticaux leur sécheresse et leur âpreté; devant sa grâce aristocratique et jeune, on ne pouvait imaginer que personne reproche à la linguistique de manquer de vie. (Meillet, 1913, p. 6-7)

Las enseñanzas específicas que el estudiante recibía de F. de Saussure tenían un valor general, preparaban para el trabajo intelectual y formaban el espíritu; las fórmulas y las definiciones que nos daba se grababan en la memoria como pautas y modelos.

Él hacía querer y vivir la ciencia que enseñaba; su pensamiento de poeta a menudo lo hacía exponer con imágenes que una vez expresadas no se podían olvidar. Tras los pormenores que indicaba, uno presentía todo un mundo de ideas generales y de impresiones; además, nunca parecía que trajera al curso una verdad ya establecida; había preparado con sumo cuidado lo que iba a decir, pero sólo cuando hablaba le daba a las ideas un aspecto definitivo; y decidía la forma de la idea en el mismo momento en el que se expresaba; el oyente quedaba suspendido a este pensamiento que seguía formándose en frente suyo y que, justo en el momento en el que se formulaba de la manera más rigurosa y más demostrativa, admitía imaginar que podría existir una fórmula aún más precisa y más demostrativa. La persona misma hacia querer la ciencia; era asombroso ver cómo esos ojos azules llenos de misterio percibían la realidad con tan rigurosa exactitud; su voz velada y armoniosa le quitaba a los hechos gramaticales la aridez y la aspereza; ante su juventud y su gracia aristocrática ¡cómo imaginar que alguien pudiera reprocharle a la lingüística su falta de vitalidad!

Si frente a sus estudiantes parisinos, élite cultural y quienes se dedicaban exclusivamente a la lingüística, Saussure no dudaba en cambiar la expresión de lo que había preparado ¿cómo no lo iba a hacer, tratando de hacerles entender unas ideas que ni sus mismos colegas podían concebir, a sus jóvenes estudiantes, ginebrinos y extranjeros, quienes nunca habían oído hablar del contenido que les presentaba?' Si el curso de lingüística general fue un reto para el Saussure teórico, también lo fue para el pedagogo, y lo que pudimos escuchar de manera preponderante en la expresión del maestro, fue precisamente el afán didáctico.

Esta hipótesis del cambio de nivel por parte del mismo profesor fue tomada en cuenta $y$, aunque no la adoptamos, nos permitió reconocer que es precisamente la sencillez de la expresión lo que sí le pertenece a Saussure.

Además es un rasgo que podemos ver también en sus escritos, aunque hay que precisar mejor esta afirmación, pues también podríamos decir que Saussure, como escritor, es muy complejo.

9 La Universidad de Ginebra era entonces muy nueva, y Saussure se queja en varias ocasiones del nivel de los estudiantes. 
En efecto, Saussure era un autor escueto y directo, pero con frases a veces realmente intrigantes, aunque no por lo eruditas, sino más bien porque la cotidianidad de las palabras utilizadas también tiende al lector una trampa, pequeña pero peligrosamente eficaz. Sus palabras son comunes y corrientes, es decir utilizadas en muchas ocasiones y por consiguiente con múltiples pistas asociativas. Las palabras siempre se pronuncian junto a otras y la organización sintáctica de las oraciones donde se utilizaron deja en las palabras rastros semánticos del vínculo que éstas tuvieron con las demás: esos rastros contribuyen a formar lo que se denomina las relaciones sintagmáticas. Entre más se utilice una palabra, más relaciones sintagmáticas habrá tenido y más sentidos podrá transmitir, pues se opone a más términos asociados. Con el sinfín de relaciones sintagmáticas que poseen, las palabras comunes y corrientes disponen entonces de un suplemento semántico incalculable.

Por ejemplo, en su famoso borrador para un artículo de homenaje a William Dwight Whitney, Saussure escribe:

Il est, en date, le premier généralisateur qui ait su ne pas tirer des conclusions absurdes sur le Langage de l'œuvre de la grammaire comparée: (Saussure, 2007, f. 4)

Hasta la fecha es el primer generalizador que haya podido dejar de sacar conclusiones absurdas sobre el Lenguaje de la obra de la gramática comparada.

Esta frase representa su mejor elogio de este pionero, pero se refiere a lo que Whitney "no" hizo. Es un elogio, pero sólo porque, implícitamente, Saussure lo compara con los demás lingüistas, que critica entonces de manera acérrima. En esta frase, podemos además entrever esta afirmación implícita: vendrá otro lingüista que sí podrá decir algo válido sobre el lenguaje en general ("hasta la fecha"). Muy a menudo las frases de Saussure contienen esta "condensación sintagmática", que sólo se despliega cuando se tiene en cuenta el contexto adecuado; en este caso, la situación equívoca de tener que escribir un elogio póstumo de un autor que lo había defraudado.
Por el gran número de sentidos que pueden esconderse en los ecos sintagmáticos, las palabras sencillas se pueden volver "enigmáticas". Por ejemplo, esta frase del segundo curso: "no hemos logrado entender qué constituye una unidad diacrónica" fue merecedora de un "sic!" en las notas del lingüista Léopold Gautier, único estudiante de ese curso que pudo medir el alcance de tal afirmación en boca del autor de la Memoria sobre el sistema primitivo de las vocales en las lenguas indoeuropeas, quien con su genialidad llevaba toda una vida de trabajo innovando el estudio de lo que en apariencia hubiera podido corresponder precisamente a las "unidades diacrónicas". Aunque se sorprende, y con mucha razón, Gautier no podía imaginar que con esa denominación de "unidad diacrónica" Saussure estaba presentando en ese momento una idea innovadora, porque si Saussure no había llegado todavía a entender lo que "constituye" precisamente una unidad diacrónica, hay que tener en cuenta que nadie tampoco había pensado ni siquiera que existieran las "unidades diacrónicas".

El discurso del profesor era pues, en apariencia, sencillo, con palabras comunes y corrientes; lo que todos los cuadernos de los estudiantes muestran... salvo un tanto los primeros y mucho los segundos cuadernos de Albert Riedlinger. Esta excepción se podría explicar por razones inherentes a la personalidad misma del estudiante, como serían la gran admiración y afecto que Riedlinger sentía por su aristocrático maestro, lo que lo llevó a seguir tantos cursos de Saussure y que quizás lo incitó a plasmar la prosodia aristocrática que admiraba en los giros tan cultos de sus segundos cuadernos. En el primer juego de notas, Riedlinger sólo utiliza estos giros cultos cuando entiende bien la idea, cuando la asimila y la puede redactar él mismo, al contrario cuando no la capta, el nivel de lengua desciende y nos encontramos entonces más bien con frases incompletas y hasta mal escritas en francés.

En el otro extremo, Caille tiene un vocabulario demasiado coloquial en la mayor parte del curso, lo que muestra su propio trabajo de asimilación del discurso de Saussure, pues no es tampoco verosímil que este vocabulario tan familiar de Caille corresponda al del profesor en 
clase: en la época los profesores no podían dejar de representar un modelo de saber y según todos sus estudiantes Saussure sí correspondía a esta figura culta. Ahora bien, el vocabulario tan familiar de Caille también podría interpretarse como otro tipo de reacción, opuesta a la de Riedlinger, frente al hablar aristocrático del profesor. Cabe anotar que, como si Saussure hubiera ganado poco a poco su simpatía emuladora, al final del curso la versión de Caille empieza a presentar un vocabulario más culto, que corresponde mejor a las expresiones usuales de Saussure.

El discurso de Saussure era pues una mezcla singular: sencillo pero bastante culto.

Para nuestra traducción, decidimos respetar esa distancia, esa otredad del discurso que cada estudiante plasmó a su manera en sus notas: para conservar el tono oral de la lección tratamos de evitar los giros cultos que connotaban a la vez lengua escrita, no resaltamos el nivel culto en las unidades léxicas, es decir que no lo plasmamos en las palabras aunque sí nos esforzamos en elaborar bastante la sintaxis, el encadenamiento ordenado de los matices de cada idea, combinado con la lógica rigurosa de las explicaciones.

El profesor que se escucha en este curso no es entonces el autor que en vida escribió y publicó artículos de erudición lingüística, es un "hablante escuchado" por dos jóvenes estudiantes.

\subsubsection{El escribir de los estudiantes}

En sus notas, como lo ilustraremos más adelante, cada estudiante refleja su manera de pensar, eincluso su visión política y social. Los dos estudiantes de 1907 parecen ser muy diferentes, en gustos, capacidades, conocimientos. Las notas de Riedlinger muestran un espíritu que respeta la tradición de la sociedad y la autoridad. Caille, al contrario, es más individuo crítico y evita las connotaciones discriminatorias sociales de las palabras. El discurso del profesor podía permitirles a ambos estudiantes que vieran reflejadas en él sus respectivas concepciones: si por su proveniencia social y su hablar aristocrático Saussure podía representar para Riedlinger un modelo admirado, con su revolucionario pensamiento lingüístico también le mostraba a Caille su propio reflejo.

\subsubsection{Louis Caille, la razón del maestro}

Alser notas en taquigrafía, cuandoempezamos a descifrar los cuadernos de Caille, teníamos la ilusión de encontrar el discurso que había pronunciado Saussure, y para múltiples frases es bastante probable que sí correspondan. Pero en su conjunto, no fue el discurso de Saussure el que oímos, sino el estilo de Caille, aunque fuera el que coincidía con una parte del estilo de Saussure, a saber, la concisión de la expresión, la precisión de las ideas, y hasta la sequedad de un pensamiento extremadamente lógico y abstracto.

Si los cuadernos de Caille contienen un vocabulario que a menudo no pareciera corresponder al de Saussure, la sintaxis que la taquigrafía le permitió registrar es en cambio muy similar a la que encontramos en las notas preparatorias de los cursos de Saussure, y la concisión de sus notas también es análoga a la de los razonamientos saussureanos en los textos que publicó.

Frente a las argumentaciones lingüísticas del profesor, Caille y Riedlinger son diferentes: Riedlinger anota muchas ideas equivocadas, hasta llega a decir lo contrario, sin darse cuenta de las contradicciones que implican sus afirmaciones en la argumentación del profesor. La versión de Caille en ese sentido es más justa, más lógica, acorde con el discurso, con las ideas de Saussure registradas en otros textos, o con la exactitud de los fenómenos mencionados. La versión de Caille permite resolver dudas y malentendidos de los cuadernos de Riedlinger, y muestra la fuerza lógica de algunas afirmaciones de Saussure, que no parecen tan decididas en Riedlinger. En la versión de Caille la belleza del razonamiento es palpable, las argumentaciones despliegan los elementos matizando la idea de manera interesante, elementos que Riedlinger soslaya muy a menudo. Riedlinger tampoco entiende ni las alusiones histórico-lingüísticas 
ni, a veces, las litotes, cuando, al contrario, Caille, es explícito registrando el sentido final de la expresión retórica.

El esqueleto sintáctico y lógico de la traducción está constituido entonces por los cuadernos de Caille, pero esto no quiere decir que estos cuadernos estén más representados que las notas de Riedlinger, ya que también en otros aspectos presentan claras lagunas.

Si bien tomaba notas en taquigrafía, Caille no copiaba como una grabadora, sino que realizó un trabajo de asimilación, discriminación y condensación de lo dicho. En particular, una característica de Caille era que, sistemáticamente, no anotaba lo que él consideraba "superfluo": las explicaciones "en otras palabras" de los conceptos difíciles, o los comentarios adyacentes a la idea, y algunos ejemplos que seguramente consideró repetitivos.

También están ausentes los resúmenes que, según su costumbre, Saussure proponía al final $\mathrm{y}$ al principio de las lecciones: al final de la clase el profesor anticipaba lo que luego trataría, y al principio de la clase recordaba lo que habían visto. Estos resúmenes entretejen la materia del curso y les permitía a los estudiantes recordar mejor todo lo dicho. Con estos mini-resúmenes las clases se entrelazan tanto que, como los estudiantes no anotaron las fechas, casi nunca es posible saber por el contenido cuándo empieza y cuándo termina una clase.

A este respecto, señalemos que para la primera lección del segundo semestre, sólo tenemos la versión de Caille y justamente sus notas empiezan un poco abruptas. Milagrosamente, con su mirada de filólogo, Engler ya había identificado, aunque no correspondían a ninguna de las versiones de los estudiantes, unos folios escritos de la mano de Saussure como posibles notas preparatorias para este curso de 1907: esos folios nos dan justamente el resumeneslabón entre el semestre de invierno y el de verano, y permiten ver lo que Caille omite con su principio abrupto, es decir, precisamente esta característica del estilo pedagógico de Saussure, tan atento a sus estudiantes, tratando siempre con múltiples precauciones de que entendieran el marco general del curso y lo que les proponía.

En este tipo de omisiones de Caille, podemos incluir también otro rasgo del estilo pedagógico de Saussure, quien a menudo introduce los temas con preguntas que enseguida responde con una argumentación clara. Este artificio de "diálogo" le permite al estudiante seguir el hilo y "participar" en el discurso del profesor. Caille poco anota las preguntas, lo más usual es que simplemente anote la respuesta como una afirmación de entrada.

Aunque siga con gran lucidez la argumentación lingüística de Saussure, a Caille poco le interesaban entonces las estrategias pedagógicas del profesor. Muy diferente es la escucha-escritura de Riedlinger.

\subsubsection{Albert Riedlinger, la pasión del maestro}

Con otra personalidad y otros intereses, Riedlinger se sintió atraído por algo que es supremamente emblemático del discurso de Saussure y que Caille también excluyó de sus notas, a saber las comparaciones e imágenes. Todos los testimonios de los estudiantes de Saussure mencionan sus imágenes por la belleza y expresividad que las caracterizaban. Riedlinger también anota el tono poético, los comentarios personales, cómo Saussure debate con sus pares, cómo se involucra y siente afectivamente lo dicho, su estilo didáctico único; o sea todo lo que muestra la pasión del profesor por el tema, punto culminante de su deseo teórico-pedagógico y que, cuando el discurso se torna muy retórico, lo cual ocurre a menudo, resulta indispensable para entender bien el sentido mismo de lo dicho.

Saussure era un ser apasionado. Su objeto de estudio no es un simple objeto, las lenguas son para él seres amables, las palabras le huelen a la tierra que las vio nacer, los sonidos florecen, los sufijos sufren, la evolución es un simpático perrito de caza perdido entre dos pistas. Las lenguas están llenas de valor afectivo y hasta de líbido, a veces son como 
bellas mujeres que él escudriña y desnuda con su mirada científica. La escritura, por ejemplo, es para él un "harapo" que esconde y disimula el verdadero semblante oral de las lenguas, absurda vestimenta que él trata de quitarles, como un verdadero voyeur, intentando observar la auténtica naturaleza del objeto contemplado. Esta enorme pasión idiomática se ve claramente reflejada en el lenguaje poético de Saussure, mencionado por todos aquellos que lo conocieron, pero también se transparenta en la mera descripción lingüística: todas las clases están llenas de cariño por las lenguas, y el profesor sabía comunicar ese afecto mediante imágenes, poéticas y retóricas, muy dicientes.

Privilegiando a ultranza la razón, Caille omite las frases con una fuerza más "afectiva", las críticas veladas a otros autores o a la lingüística en general, y sólo anota las imágenes como recordatorio. Por ejemplo, en la imagen sobre el análisis subjetivo y el análisis objetivo como una distribución interior del edificio, (páginas de los manuscritos Caille, p. 157; Riedlinger: p. 131-132) Caille escribe entre paréntesis: "historia del edificio", mientras que Riedlinger desarrolla la imagen en todo un párrafo; como si lo que transmitiera la belleza y la emoción hubiera tenido una gran importancia para Riedlinger, aún más considerable que la de la reflexión razonada, que Caille privilegiaba. Sabemos, por sus nietos, que Riedlinger se convirtió luego en un maestro de bachillerato muy querido por sus alumnos y quien se esforzaba en compartirles su amor por la belleza del lenguaje.

La carta que Riedlinger le dirige en 1911 permite apreciar el verdadero cariño que este estudiante sentía por Saussure, lo que posiblemente lo haya llevado a escribir los segundos cuadernos con el estilo muy profesoral que él atribuía a su maestro, mientras que Caille le quita todo lo que él consideraba un superfluo y altisonante adorno: paradójicamente, como ya lo mencionamos, ambas actitudes también hubieran podido corresponder simplemente a la reacción respectiva de cada estudiante, en el ámbito social, frente a la personalidad aristocrática del profesor.
En resumen, Caille es sencillo, escribe con un nivel prioritariamente coloquial, domina una expresión condensada, precisa y lógica que transmite la belleza de los razonamientos y retiene frases estructuradas según la sintaxis típicamente saussureana. Riedlinger es desigual: culto a veces, coloquial otras, algo pomposo en ocasiones $y$, en otras, muy elíptico, no es muy preciso, pero anota todo lo que puede, en particular todo lo "afectivo" que Caille, omite. Las notas de Riedlinger permiten entonces corregir, completar o matizar lo escrito por Caille.

Aunque divergen, estas versiones también se completan, conversan entre sí.

\subsubsection{Discrepancias y complementaridad}

¿Cómo era realmente el discurso de Saussure? Para este primer curso, solo tenemos dos versiones y pocas veces ambos estudiantes anotan exactamente la misma frase; en general esto ocurre únicamente cuando se trata de definiciones, como la de la alternancia o la de la raíz, y entonces lo más verosímil es que Saussure las haya dictado. Cuando las frases de Caille y Riedlinger son completamente diferentes, a veces no hay ninguna manera de deducir algo con cierto grado de certeza.

Por ejemplo, cuando Saussure introduce los problemas de la escritura como documento de la palabra hablada, Riedlinger anota que es correcto hacerlo; Caille anota, al contrario, que es otro ejemplo de error. En nuestra traducción decidimosnoescoger entreestas dos afirmaciones contrarias, sinoquele dejamos a la argumentación la tarea de mostrar los dos aspectos, el falso y el verdadero, pues nos pareció que esa hubiera podido ser la intención de Saussure, ya que ambas afirmaciones corresponden a partes distintas de la argumentación y son justamente ambas las que le dan coherencia al razonamiento.

Las diferencias entre los estudiantes, en vez de anularse, casi siempre se explican enriqueciendo el discurso del profesor, en varios niveles. Ambas versiones se complementan de entrada según la asistencia al curso: Caille parece haber 
llegado tarde al curso sobre la alternancia y Riedlinger parece haber faltado a toda la lección que introduce el fenómeno analógico, de la cual no poseemos entonces sino la única versión de Caille. Podemos subrayar tambien otros dos niveles.

1. Ambos estudiantes divergen y se complementan frente al saber lingüístico y filológico que poseían.

Caille anota muy bien todos los ejemplos de la rama germánica, pero el inglés y sobre todo el griego antiguo no parecen haber hecho parte de su bagaje personal profundo. Riedlinger anota el sentido de las palabras en alemán como si no las entendiera y escribe muy mal los ejemplos en las lenguas germánicas, pero es más cuidadoso con el griego y el latín.

Caille está cursando su último año de estudios: entiende mejor la terminología lingüística y filológica, y le pone particular atención a ciertos fenómenos, como la alternancia, tan importante en alemán. Para Riedlinger, quien acaba de empezar sus estudios, todo es nuevo y no parece tener mucho criterio para privilegiar algo en particular. En su diversa comprensión, se ve reflejada la madurez de Caille así como su predilección por las lenguas modernas, y la inexperiencia de Riedlinger como su gusto por la cultura clásica.

2. Según la cultura general de cada uno, las notas también divergen.

Por ejemplo, cuando Saussure habla de las causas del cambio fonético que se han argüido y menciona la raza, hay una ilustración absolutamente diferente en ambos estudiantes. Riedlinger escribe: "Exemple d'un nègre transplanté dès sa naissance". Caille escribe: "un jeune peau-rouge transporté en France". ¿Qué dijo Saussure, negro trasplantado desde el nacimiento o piel roja joven transportado a Francia? Como no es el mismo ejemplo y ambos evocan ideas adyacentes, podemos afirmar que al menos uno de los estudiantes escogió una variante personal, pero nada permite pensar que no fueran ambos estudiantes los que escogieron su propia variante y que Saussure hubiera dado otro ejemplo diferente, o varios diferentes. $\mathrm{O}$ incluso ¿Saussure dio ambos ejemplos y cada estudiante anotó uno solo? Tenemos entonces varias opciones sobre lo que pudo haber dicho Saussure:

1. Negro y pielroja: en este caso, ambos estudiantes retuvieron sólo una raza, pero ¿por qué?

2. Negro: en este caso, sería Caille quien cambió la raza, pero ¿por qué?

3. Pielroja: en este caso, sería Riedlinger quien cambió la raza, pero ¿por qué?

4. Otra raza cualquiera: amarillo, semita, polinesio, etc.: en este caso ambos estudiantes cambiaron la raza, pero ¿por qué?

5. Una raza poco corriente pero con connotaciones histórico-literarias: ¿cómo el iroqués mencionada por Chateaubriand? ${ }^{10}$ Opción muy interesante pues explicaría a la vez el Pielroja de Caille, poco dado a anotar detalles (una raza norteamericana al fin y al cabo), y el Negro de Riedlinger, joven estudiante no muy versado que pudo entender iroqués como un pueblo africano.

Sin embargo, para traducir esta frase nos decidimos por la primera opción, o sea incluir ambas razas, pero no porque creamos que Saussure las dijo ambas, sino porque la suma neutraliza las connotaciones de discriminación social que la raza vehicula actualmente y que, aunque posible para la época, sería difícil adjudicar con certeza a Saussure, y en cualquier caso no es pertinente para el sentido de lo dicho. Además esta opción respeta lo anotado por ambos estudiantes, corresponde al deseo pedagógico del profesor que siempre multiplicaba los ejemplos para que la idea quedara clara, y por último no cambia en absoluto la idea general ilustrada con el ejemplo, sino que al contrario la complementa. En el cuaderno de Riedlinger hay además unos puntos suspensivos que indican que sólo anotó una parte de lo dicho.

10 Interpretación que nos propuso Guy Poitry, docente de literatura francesa en la Facultad de letras de la Universidad de Ginebra. 
La opción 5 era muy tentadora, y personalmente nos parece además la más verosímil, pues explicaría por qué escogieron los estudiantes sus versiones y correspondería bien a Saussure, a quien le gustaba ese tipo de alusiones veladas que sólo entiende quien conoce ampliamente lo precedente. Si estuviéramos solamente reconstruyendo hubiéramos optado por introducir el iroqués. Sin embargo, no la escogimos, pues afirmar así que el profesor aludió explícitamente a Chateaubriand hubiera sido un abuso de traducción frente a los originales, y aunque se haya necesitado mucha imaginación para escribirla, esta traducción no es una obra de ficción, sino una mera traducción.

Esta traducción reconstructiva no es "verdadera", ya que en este campo humano de la reconstrucción la verdad es inalcanzable por definición, pero tampoco es fruto de la imaginación deductiva, sólo pretende ser verosímil según los originales disponibles, que publicamos frente a nuestra traducción. Ateniéndonos al material existente, que permite al menos que comprendamos globalmente las ideas expuestas, decidimos que los cuadernos de Louis Caille constituyeran el esqueleto lógico de esta traducción, añadiéndole, eso sí, el calor afectivo y el sentimiento poético de Albert Riedlinger.

Esta traducción es entonces reconstructiva no porque reconstruya "el verdadero discurso de Saussure", sino porque reconstruye el acto de hablar que incluye los participantes, el profesor y sus estudiantes. Ese acto de hablar, que es el núcleo de la transmisión oral, esconde la fuerza y la permanencia de este tipo de transmisión, que por un error de óptica siempre se creyó efímera.

\section{Agradecimientos}

Agradecemosal Departamento de los manuscritos de la Biblioteca de Ginebra y a los señores Philippe y Jacques de Saussure por darnos la autorización de publicar las imágenes y la transcripción de los manuscritos que les pertenecen.

\section{Referencias}

Ansermet, François y Magistretti, Pierre 2004. A chacun son cerveau. París: Francia, Odile Jacob.

- 2010. Les enigmes du plaisir. París: Francia, Odile Jacob.

Bally, Charles y Sechehaye, Albert 1916. Cours de linguistique générale de Ferdinand de Saussure. París, Francia: Payot.

- 1945. Curso de lingüística general. Traducción al español de Amado Alonso. Buenos Aires, Argentina: Losada.

Barthes, Roland 1964. "Eléments de sémiologie", Communications $N^{\circ}$ 4. París, Francia: Seuil, [L'aventure sémiologique, París, Francia: Seuil, 17-84. 1985].

Bouquet, Simon 2010. “Du pseudo-Saussure aux textes saussuriens originaux". In Le projet de Ferdinand de Saussure. Editado por Bota, Cristian, Bronckart, Jean-Paul et Bulea, Ecaterina. Ginebra, Suiza: Droz, 31-48.

Buyssens, Eric 1942. “De l'abstrait et du concret dans les faits linguistiques: La parole - le discours - la langue", Acta linguistica III: 1623.

- 1943. Les langages et le discours. Bruselas, Bélgica: Office de Publicité.

Eugenio 1977. Tradición y novedad en la ciencia del lenguaje. Estudios de historia de la lingüística. Madrid, España: Gredos.

Depecker, Loic 2008. "Pour une généalogie de la pensée de Saussure (1)", Bulletin de la Société de Linguistique de Paris 103/1: 7-62.

- 2009a. "Pour une généalogie de la pensée de Saussure (2)"', Bulletin de la Société de Linguistique de Paris 104/1: 39-105.

- 2009b. Comprendre Saussure. París, Francia: Armand Colin. Demoule, Jean Paul 2014. 
Mais où sont passées les Indo-Européens?: Le mythe d'origine de l'Occident. París, Francia: Éditions du Seuil.

Engler, Rudolf 1968-1974. Cours de linguistique générale. Edition critique (CLG-E). Fascículos agrupados ulteriormente en dos tomos. Wiesbaden, Alemania: Otto Harrassowitz.

Fehr,Johannes1997.FerdinanddeSaussure:Linguistik und Semiologie. Notizen aus dem Nachlass, Texte, Briefe und Dokumente; Gesammelt, übersetzt und eingeleitet von Johannes Fehr. Frankfurt am Main, Alemania: Suhrkamp.

- 2002. Saussure entre linguistique et sémiologie, traducido del alemán por Pierre Caussat. París, Francia: Presses Universitaires de France.

Godel, Robert 1954. "Notes inédites de F. de Saussure", transcription par Robert Godel. Cahiers Ferdinand de Saussure 12:49-71.

- 1957a. Les sources manuscrites du Cours de linguistique générale. Ginebra, Suiza: Librairie Droz.

- 1957b. "Introduction au deuxième cours de linguistique générale de Ferdinand de Saussure". Cahiers Ferdinand de Saussure 15: 3-103.

- 1958. "Nouveaux documents saussuriens: les cahiers E. Constantin". Cahiers Ferdinand de Saussure 16: 23-32.

- 1960a. "Inventaire des manuscrits de Ferdinand de Saussure remis à la Bibliothèque Publique et Universitaire de Genève". Cahiers Ferdinand de Saussure 17: 5-11.

Hjelmslev, Luis 1928. Principes de grammaire générale. Copenhague, Dinamarca: Munksgaard.

- 1942 [reimp. 1970]. "Langue et Parole". In Essais linguistiques. Copenhague, Dinamarca: Nordisk Sprog-og Kulturforlag
- 1943 [1971]. Prolégomènes à une théorie du langage. París, Francia: Minuit.

Jakobson, Roman 1931 "Principes de phonologie historique". Travaux du Cercle linguistqiue de Prague, IV: 247-267, reproducido en Trubetzkoy, Nikolai 1939. Principes de phonologie, París, Francia: Klincksieck.

Kaudé, Annette 2006. Saussure letztes Wort. Deutsche Übertsetzung und Deutung der Hörermanuskripte zur dritten Genfer Vorlesung über allgemeine Sprachwissenschaft (1910-1911). Tesis de la Universidad de Dusseldorf. Consultado en http:// docserv.uni-dusseldorf.de/servlets/ DerivateServlet/Derivate-3481/1481.pdf.

Lacan, Jacques 1966. Ecrits. París, Francia: Editions du Seuil.

Lévi-Strauss, Claude 1958. Anthropologie structurale. París, Francia: Plon.

Meillet, Antoine 1913. "Ferdinand de Saussure". Annuaire de l'École pratique des Hautes Études, 1913-1914 : 115- 125.

- 1916. "Compte-rendu du Cours de Linguistique Générale", Bulletin de la Société de Linguistique de Paris, Tome XX, 1916, 32-33, 36.

Mejía Quijano, Claudia 1997. “Unde exoriar?”, Cahiers Ferdinand de Saussure, 50: 5-20.

- 1998a. La linguistique diachronique: le projet saussurien. Publications du Cercle Ferdinand de Saussure. Ginebra, Suiza: Librairie Droz.

- 1998b. “L'image du jeu d'échecs chez Ferdinand de Saussure ou le bouclier de Persée”, In J. Berchtold, Echiquiers d'encre, Ginebra, Suiza: Librairie Droz.

- 1999a. "L'aposème, unité de parole", Cahiers Ferdinand de Saussure 52: 237-252.

- 1999b. "La silhouette du mot", In Parole come radici. Linguaggio e Filosofia tra storia e teoria, a cura di D. Chiricò, N. Lamedica, C. Stancati. Rende, Italia: Ticonzero. 
- 2006a. "L'ouvrage d'un philologue artiste". Cahiers Ferdinand de Saussure 58: 5-20.

- 2006b. "Sous le signe du doute". Cahiers Ferdinand de Saussure, 58 : 43-67.

- 2008. Le cours d'une vie. Portrait diachronique de Ferdinand de Saussure. Tome 1: Ton fils affectionné. Nantes, Francia: Editions Cécile Défaut.

- 2009a. "Les plis temporels". Pour une édition numérique des textes de Ferdinand de Saussure. Cosenza: Italia, Università dell'a Calabria, 1-3 de octubre. Disponible en http:// www.cerclefds.unical.it/seminaire/ download/mejia.pdf

- 2009b. "La permanence de l'éphémère." Pour une édition numérique des textes de Ferdinand de Saussure. Cosenza- Italia, Università dell'a Calabria, 1-3 de octubre de 2009. Disponible en http://www.cerclefds. unical.it/seminaire/download/mejia2.pdf

- 2012a. “La parole, acte créateur de langue ». Bulletin de la Société de linguistique de Paris 107/1 : 43-102.

- 2012b. Le cours d'une vie. Portrait diachronique de Ferdinand de Saussure. Tome 2: Devenir père. Nantes, Francia: Editions Cécile Défaut.

- 2014. Ferdinand de Saussure. Une vie en lettres 1866- 1913. Nantes, Francia: Editions Cécile Défaut.

- 2015. “L'œuvre en réseaux: nouvelle découverte de manuscrits saussuriens". Beiträge zur Geschichte der Sprachwissenschaft. 25-1: 149176.

Mejía, Claudia, Germond, Marc y Ansermet, François 2006. Parentalité stérile et procréation médicalement assistée. Francia: Erès.

Mejía Quijano, Claudia, Jaramillo Giraldo, Daniel y Pérez Zapata, Alexander 2016. "La part de l'élève dans la parole du maître: Hommage aux élèves de Ferdinand de
Saussure à l'occasion du centenaire du Cours de Linguistique Générale". Beiträge zur Geschichte der Sprachwissenschaft. 26-1: 287-306: 1-20.

Petit, Daniel 2010a. "Accent et intonation: le modèle lituanien chez Ferdinand de Saussure". Cahiers Ferdinand de Saussure 62: 63-89.

- 2010b. "New Insights on Lithuanian Accentuation from the unpublished manuscripts of Ferdinand de Saussure 18571913”. Baltic Linguistics 1: 143-166.

-2013. "A propos d'analogie: entre pathologie et thérapie linguistique". Ferdinand de Saussure: neurosciences, psychanalyse et sémiologie. Séminaire interdisciplinaire AGALMASEMSA commémorant le centenaire de la mort de Ferdinand de Saussure, 3 de octubre de 2013. Le Cénacle: Ginebra. Disponible en https:// youtu.be/Sy9M-OjOE2E.

Petit, Daniel y Mejía Quijano, Claudia 2009. “Du nouveau à propos du voyage en Lituanie de Ferdinand de Saussure". Cahiers Ferdinand de Saussure 61: 133-157.

Prieto, Luis Jorge. 1975. Pertinence et pratique. París, Francia: Editions de Minuit.

- 1982. "Langue et parole sur le plan du contenu". Cahiers Ferdinand de Saussure, 35: 131-143. Redard, Georges 1978. "Deux Saussures?" Cahiers Ferdinand de Saussure 32: 27-42.

Regard, Paul Frédéric 1918. Contribution à l'étude des prépositions dans la langue du Nouveau Testament, París, Francia: E. Leroux.

Rousseau, André 2006. "A la lumière d'un cours inédit sur le gotique". Nouveaux regards sur Saussure. Publications du Cercle Ferdinand de Saussure V. Ginebra, Suiza: Droz.

Saussure, Ferdinand de 1954. "Notes inédites", transcripción por Robert Godel, Cahiers Ferdinand de Saussure 12: 49-61 
- 1957. "Introduction au deuxième cours de linguistique générale de Ferdinand de Saussure". Editada por Robert Godel, Cahiers Ferdinand de Saussure 15 : 3-103.

- 1960. "Souvenirs de F. de Saussure concernant sa jeunesse et ses études". Editado por Robert Godel. Cahiers Ferdinand de Saussure 17: 12-25.

- 1968. Cours de linguistique générale. Edición crítica editada por R. Engler. Tomo 1. Wiesbaden, Alemania: O. Harrassowitz.

- 1974. Cours de linguistique générale. Edición crítica editada por R. Engler.Tomo 2, notas autógrafas. Wiesbaden, Alemania: O. Harrassowitz.

- 1978. "Essai pour réduire les mots du grec, du latin et de l'allemand à un petit nombre de racines." Transcripción de Boyd Davis. Cahiers Ferdinand de Saussure 32: 73-101.

- 1980. “Le consonantisme grec et latin selon F. de Saussure: le cours de phonétique professé en 1909-1910". Editado por MarieJosé Béguelin, Cahiers Ferdinand de Saussure 34: 17-97.

- 1986. Le leggende germaniche: Scritti Scelti e annotati. Editado por Anna Marinetti et Marcello Meli. Italia: Zielo-Este.

- 1987. Cours de linguistique générale (III) de F. de Saussure. Editado por Eusuke Komatsu. Tokyo, Japón: Faculty of letters, Gakushuin University.

- 1988. "Dix-huit notes étymologiques inédites de Ferdinand de Saussure". Editado por René Amacker et Simon Bouquet. Cahiers Ferdinand de Saussure 42: 215-244.

- 1990. "Le sens du mot". Un corso di morfologia indoeuropea. Transcripción de Francesca Angeli et Cristina Vallini, AION. Annali del dipartimento du Studi del Mondo classico et del Mediterraneo Antico Sezione linguistica, 12: 365-425.
- 1993a. F. de Saussure. Cours de linguistique générale: premier et troisième cours d'après les notes de Riedlinger et Constantin. Editado por Eusuke Komatsu.Tokyo, Japón: Université Gakushuin.

- 1993b. Third Course in General Linguistics. Editado por Eusuke Komatsu y Roy Harris. Oxford, Inglaterra: Pergamon.

- 1995a. Ferdinand de Saussure. Phonétique. Il manoscritto di Harvard Houghton Library. BMs. Fr. 266. Editado por Maria Pia Marchese. Florence, Italia: Unipress.

- 1995b. "Grammaire comparée du grec et du latin (1907-1908). Notes d'Albert Riedlinger". Extractos transcritos por Hiroschi Abe. In Saussure and Linguistics Today, Italia: Bulzoni.

- 1996. F. de Saussure. Premier cours de linguistique générale (1907), d'après les cahiers d'Albert Riedlinger. Editado por Eusuke Komatsu y Georges Wolf. Oxford, Inglaterra: Pergamon.

- 1997a. F. de Saussure. Deuxième cours de linguistique générale: (1908-1909), d'après les cahiers d'Albert Riedlinger et Charles Patois. Editado por Eusuke Komatsu y George Wolf. Oxford, Inglaterra: Pergamon.

- 1997b. "La note alka, BPU Ms fr. 3951-9". Reproducción en facsímil. Cahiers Ferdinand de Saussure 50: 111-126.

- 2002a. Théorie des sonantes. Il manoscritto di Ginevra BPU Ms Fr. 3955-1. Editado por Maria Pia Marchese, Firenze, Italia : Unipress.

- 2002b. Ecrits de linguistique générale. Editado por Rudolf Engler y Simon Bouquet. París, Francia: Gallimard.

- 2004. Escritos de lingüística general. Traducido por Clara Lorda. Barcelona, España : Gedisa.

- 2006. Writings in general linguistics. Traducido por Carol Sanders y Matthew Pires, Oxford, Inglaterra: Oxford University Press. 
- 2005. Scritti inediti de linguística generale. Traducido por Tullio de Mauro. Roma, Italia: Laterza

- 2003a. "Notes sur l'accentuation lituanienne". Transcripción de Jäger, Ludwig, Buss, Mareike y Ghiotti, L. Saussure. Cahier de l'Herne 76 : 323-350.

- 2003b. “Légendes et récits d'Europe du Nord: de Sigfrid à Tristan". Transcripción de Béatrice Turpin, Saussure. Cahier de l'Herne: 351-429.

- 2006a. “Emile Constantin. Cours delinguistique générale de $\mathrm{Mr}$ le professeur Ferdinand de Saussure 1910-1911". Editado por Claudia Mejía Quijano. Cahiers Ferdinand de Saussure 58: 83-289.

- 2006b. “Notes préparatoires pour le cours de Linguistique générale 1910-1911". Editado por Daniele Gambarara Cahiers Ferdinand de Saussure 58 : 92-259.

- 2007. BGE Ms. fr. 3951-10. "Note Whitney". Reproducción digital en CD-ROM. Cahiers Ferdinand de Saussure 60.

- 2008a «Tra biografia e teoria: due inediti di Saussure del 1893 (AdeS 377/8 e 377/13)". Editado por Maria Pia Marchese. Cahiers Ferdinand de Saussure 60: 217-235.

- 2008b Une vie en lettres 1872-1881 - Ecrits littéraires d'adolescence. Editado por Claudia Mejía Quijano et Elodie Paillard. In Le cours d'une vie, Tome 1, Nantes, Francia: Cécile Defaut.

- 2009. "Eschyle, Agamemnon. Traduction de Ferdinand de Saussure". Editado por Natalia Restrepo Montoya, y Claudia Mejía Quijano. Cahiers Ferdinand de Saussure 61: 199-238.
- 2011. Science du langage. De la double essence du langage et autres documents du ms. BGE Arch. de Saussure 372. Editado por René Amacker. Ginebra, Suiza: Droz.

- 2012. Une vie en lettres 1881-1890. Editado por Claudia Mejía Quijano. In Le cours d'une vie. Portrait diachronique de Ferdinand de Saussure. Tomo 2, Nantes, Francia: Editions Cécile Défaut.

- 2013a. Anagrammes Homériques. Presentación y edición de Pierre-Yves Testenoire. Limoges, Francia: Lambert-Lucas.

- 2013b. Il corso di "Etymologie grecque et latine" 1911- 1912 di Ferdinand de Saussure negli appunti di Louis Brutsch. Editado por Francesca Murano. Alessandria, Italia: Edizioni dell'Orso.

- 2014. Une vie en lettres 1866-1913. Diacronía establecida por Claudia Mejía Quijano. Nantes, Francia: Editions Cécile Défaut. Sofia, Estanislao 2013. "Cents ans de philologie saussurienne". Cahiers Ferdinand de Saussure 66: 181-197.

- 2015. La "Collation Sechehaye" du "Cours de linguistique générale' de Ferdinand de Saussure. Louvain, Bélgica: Peeters.

Troubetzkoy, Nikolai 1939. Principes de phonologie. París, Francia: Klincksieck.

Vincent, François 2014. “Le premier cours de linguistique générale professé par Ferdinand de Saussure à Genève. Cours I et sténographie Caille. Transcription et commentaire". Cahiers Ferdinand de Saussure 67: 175-190.

Wunderli, Peter 1990. Principes de diachronie. Contribution à l'exégèse $d u$ "Cours de linguistique générale» de Ferdinand de Saussure, Frankfurt am Mein, Alemania: Peter Lang. 